\title{
Identification and Characterization of Cerebral-to-Buccal Interneurons Implicated in the Control of Motor Programs Associated with Feeding in Aplysia
}

\author{
Steven C. Rosen, ${ }^{1}$ Thomas Teyke, ${ }^{2}$ Mark W. Miller, ${ }^{3}$ Klaudiusz R. Weiss, ${ }^{3}$ and Irving Kupfermann ${ }^{1}$ \\ ${ }^{1}$ Center for Neurobiology and Behavior, New York State Psychiatric Institute and College of Physicians and Surgeons of \\ Columbia University, New York, New York 10032, ${ }^{2}$ nstitut für Zoologie (III) Biophysik, Johannes Gutenberg-Universität, \\ 6500 Mainz, Germany, and ${ }^{3}$ Department of Physiology and Biophysics and Fishberg Research Center for Neurobiology, \\ Mount Sinai School of Medicine, New York, New York 10023
}

\begin{abstract}
We identified candidate neurons in the cerebral ganglion that regulate feeding responses mediated by the buccal ganglion. Backfilling the cerebral-buccal connectives revealed that each cerebral hemi-ganglion contains approximately 20 neurons that project axons to the buccal ganglion. Three M-cluster neurons (CBI-1, CBI-2, CBI-3) and one E-cluster neuron (CBI-4) were identified as cerebral-to-buccal interneurons (CBIs) based on position, morphology, synaptic connections, and ability to drive buccal motor programs (BMPs). CBI-1 responds to touch of the tentacles, lips, and buccal mass. It receives monosynaptic EPSPs from interganglionic, cerebral-to-buccal mechanoafferent (ICBM) neurons and monosynaptically excites buccal cells, some of which are also excited by the ICBMs. Tonic firing of CBI-1 usually evokes a single cycle of BMP activity. CBI-1 phaseshifts the rhythmic BMP driven by firing a dopaminergic neuron in the buccal ganglion. CBI-1 itself exhibits dopamine-like histofluorescence following formaldehyde-glutaraldehyde fixation. CBI-2 is excited by food stimuli applied to the lips. Constant-current intracellular stimulation of $\mathrm{CBI}-2$ produces phasic firing of the cell that reliably evokes a rhythmic BMP that incorporates buccal and cerebral motor neurons, putative pattern-generating and pattern-initiating neurons, and neuromodulatory cells (metacerebral cells). $\mathrm{CBI}-4$ also evokes a rhythmic BMP, but the details of its actions and synaptic effects differ from that of CBI-2. CBI-3 does not evoke a BMP, even though it is excited by food stimuli applied to the lips, and it makes monosynaptic connections (both excitatory and inhibitory) to many follower cells of the other CBls. Firing of CBI-3 phase-delays the BMP driven by $\mathrm{CBI}-2$. Since its activity is incorporated into BMPS and it provides direct inputs to elements of the feeding circuitry, it may play a role in pattern generation. The distinctive features of the CBIs suggest that the consummatory phase of feeding may be controlled by a population of interneurons that subserve different roles.
\end{abstract}

Feeding behavior in gastropod mollusks has proven useful as a model system for the study of the neuronal control of behavior

\footnotetext{
Received Mar. 26, 1991; revised June 21, 1991; accepted June 27, 1991.

This work was supported in part by U.S. Public Health Service Grants MH 35564 and GM 320099. We thank Dr. J. Koester for alerting us to the literature on the use of probenecid.

Correspondence should be addressed to Dr. Steven C. Rosen, Center for Neurobiology and Behavior, New York State Psychiatric Institute, New York, NY 10032.

Copyright (C) 1991 Society for Neuroscience $0270-6474 / 91 / 113630-26 \$ 05.00 / 0$
}

(Kater, 1974; Kupfermann, 1974a; Gelperin et al., 1978; Willows, 1978; Gelperin, 1981; Benjamin, 1983; Croll and Davis, 1987). Feeding is of interest because it is a relatively complex behavior that permits the exploration of a wide range of interrelated problems. Moreover, feeding has been investigated in a variety of molluscan species, thereby facilitating comparisons that can aid in determining which features are species specific and which may have more general significance. The problems that have been investigated include sensory integration (Kater and Rowell, 1973; Audesirk and Audesirk, 1980; Fredman and Jahan-Parwar, 1980; Spray et al., 1980a,b; Bicker et al., 1982; Chiel et al., 1986; Weiss et al., 1986c; Elliott and Benjamin, 1989; Rosen et al., 1989a; Delaney and Gelperin, 1990c), motor control (Kater, 1974; Granzow and Kater, 1977; Cohen et al., 1978; Willows, 1980; Fiore and Geppetti, 1981; McClellan, 1982a; Benjamin, 1983; Jahan-Parwar et al., 1983; Elliott and Benjamin, 1985; Murphy et al., 1985; Croll and Davis, 1987; Arshavsky et al., 1988; McCrohan, 1988; Kirk, 1989; Nagahama and Takata, 1990), and behavioral plasticity including learning and motivation (Kupfermann, 1974a; Weiss et al., 1982; Benjamin, 1983; Davis et al., 1983; Croll et al., 1985a; Kovac et al., 1986; Benjamin and Elliott, 1989; Kemenes and Benjamin, 1989). Neuronal circuits controlling feeding behavior have also been studied to investigate how the nervous system commands or selects specific behaviors. In a number of gastropod mollusks, the firing of individual neurons can elicit ingestive or egestive behaviors, or motor programs associated with these behaviors (Willows, 1980; Rose and Benjamin, 1981; McClellan, 1983a; Croll et al., 1985c; Susswein and Byrne, 1988; McCrohan and Kyriakides, 1989; Delaney and Gelperin, 1990b; Plummer and Kirk, 1990). The precise functional role of these neurons in molluscan feeding is not known and in some instances is controversial (McClellan, 1982a,b, 1983a,b; Gillette and Gillette, 1983; Croll et al., 1985a-c), but it is clear that these cells provide a good vantage point from which to examine the behavioral control of feeding. Neurons whose firing elicits complex motor outputs have been termed command neurons or elements of command systems (Kupfermann and Weiss, 1978). It has been suggested that because the term "command neuron" has functional connotations, it should be reserved only for neurons that have been shown to be necessary and sufficient for a specific behavior to occur (Kupfermann and Weiss, 1978, 1986). For the purposes of this article, neurons whose individual firing produces a complex motor output, but which have not been shown to be necessary and sufficient for behavior, will be termed "command-like neurons." This will serve to indicate that they 


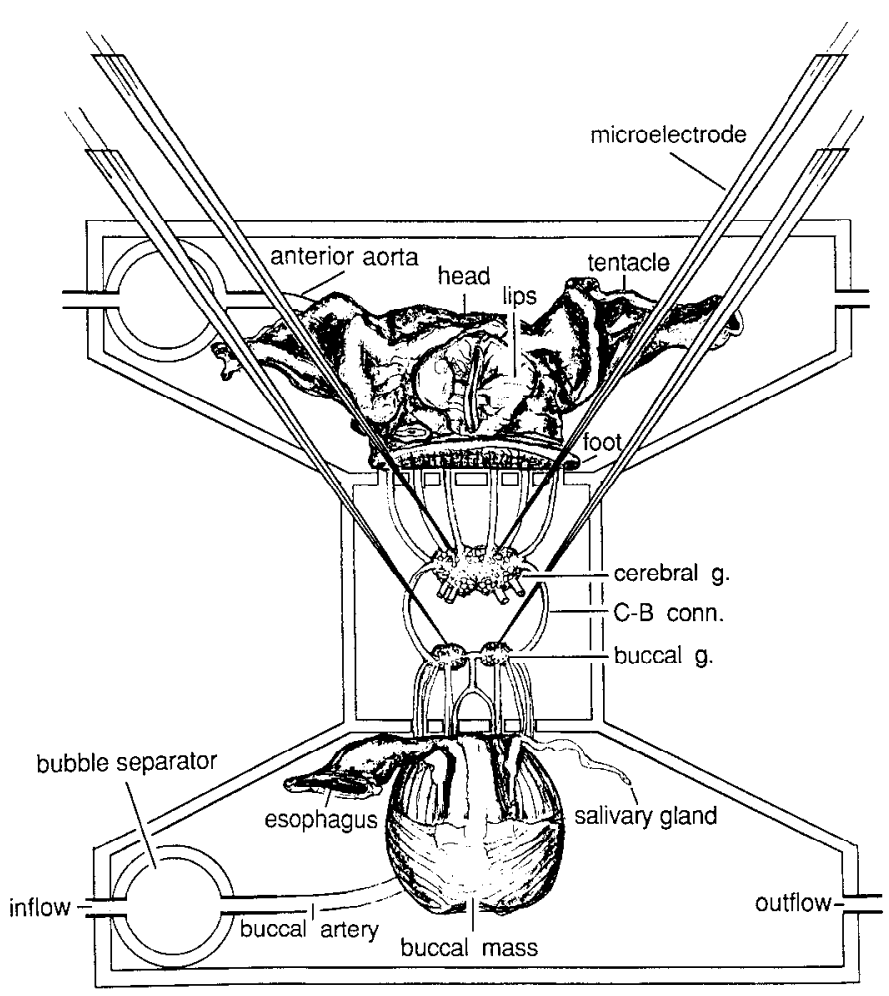

Figure 1. Schematic drawing of the arrangement of the reduced preparation in the recording chamber. Separate compartments of the recording chamber permitted isolation of the head structures. The middle compartment was sometimes subdivided for isolation of the cerebral (cerebral g.) from the buccal ganglion (buccal g.), with the C-B connective ( $C$ - $B$ conn.) intact. The partitions between compartments contained Vaseline-filled fine grooves for passage of nerves and connectives so that innervation of the head, buccal mass, and central ganglia remained intact. The perfusion system of the lips and tentacles incorporated a bubble separator and a cannula in the anterior aorta. The buccal mass was similarly perfused with a cannula in the buccal artery.

are related to other neurons that have been termed command neurons or command elements and leaves open for future studies the difficult question of the precise contribution of these neurons to behavior.

Feeding in Aplysia has been extensively studied, and there is considerable information on the behavior per se, as well as on the sensory and motor neuronal aspects of the behavior (Kupfermann, 1974a; Susswein et al., 1976, 1978; Leonard and Lukowiak, 1986; Carefoot, 1987; Teyke et al., 1990). Compared to other molluscan species, however, relatively little is known about the interneuronal circuitry that controls feeding in Aplysia (see, however, Gardner and Kandel, 1977; Fiore and Meunier, 1979; Chiel et al., 1988; Susswein and Byrne, 1988; Plummer and Kirk, 1990). Investigations in Aplysia and in related gastropods indicate that most of the motor neurons and central pattern generators (CPGs) for consummatory phases of feeding, including biting, swallowing, and rejection responses, are located in the buccal ganglion (Cohen et al., 1978; Weiss et al., 1982; Susswein and Byrne, 1988; Kirk, 1989). However, several lines of evidence suggest that the neural elements that may initiate and modulate these behaviors are located in the cerebral ganglion. For example, lesioning of the cerebral-buccal (C-B) connectives in Aplysia, which disrupts the flow of information to the buccal ganglion from the cerebral ganglion, results in an inability of animals to bite (Kupfermann, 1974b), although they

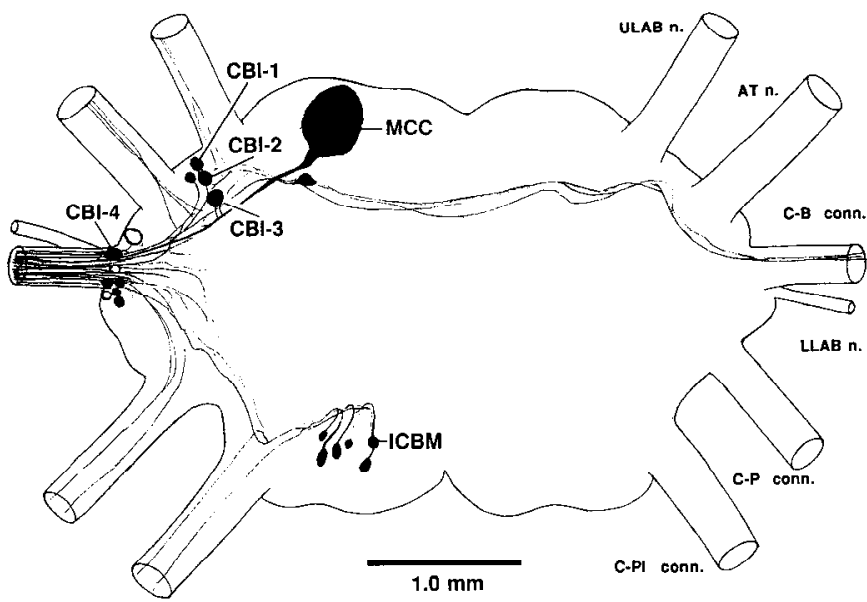

Figure 2. Drawing of the neurons in the cerebral ganglion that project axons to the buccal ganglion via the ipsilateral C-B connective. The somata were stained with nickel following backfilling of the connective. Only cells filled from the right connective are shown in this ventral view. The identities of the CBIs in the drawing are based on detailed information concerning the characteristic positions of the cells in the cerebral ganglion. Abbreviations (after Jahan-Parwar and Fredman, 1976): $U L A B$, upper labial; $A T$, anterior tentacular; $L L A B$, lower labial; $C$ - $B$, cerebral-buccal; $C-P$, cerebral-pedal; $C$ - $P l$, cerebral-pleural; $n$., nerve; conn., connective.

orient to food normally. Moreover, the cerebral ganglion of Aplysia has been found to contain sensory neurons (Rosen et al., 1979, 1982) and modulatory neurons that provide important input to the feeding circuitry (Weiss and Kupfermann, 1976; Pentreath et al., 1982; Weiss et al., 1986b), and as mentioned above, command-like neurons have been described in the cerebral ganglia of other gastropods. We therefore initiated a search for command-like neurons in Aplysia, concentrating on cerebral ganglion neurons that send axons to the buccal ganglion. We report here the identification of four distinctive cerebral-to-buccal interneurons (CBIs) that provide synaptic inputs to buccal interneurons and motor neurons involved in feeding. Two of these, CBI-2 and CBI-4, are command-like in that they are capable of reliably driving thythmic buccal motor programs (BMPs). For the purposes of this article, the term "BMP" refers to any simultaneous phasic activity of multiple buccal cells. Several different BMPs have been described (Kupfermann, 1974a; Susswein and Byrne, 1988). Since, however, the purpose of the present article is to introduce the CBIs and present only enough functional data to indicate their probable importance, we do not attempt to define precisely the BMPs that are evoked.

In the Results we will first present an overall view of the morphology and electrophysiological characteristics of the CBIs. We will then consider in turn each of the four cells and describe their characteristics in detail. Details of the functional features of some of these cells are currently under investigation and will be described in a future report (S. C. Rosen, K. R. Weiss, and I. Kupfermann, unpublished observations).

Some of the findings presented in this article have been presented in preliminary communications (Rosen ct al., 1987, 1988, 1989b).

\section{Materials and Methods}

Subjects. The experimental subjects were wild-type Aplysia californica weighing 250-400 gm (Marinus, Inc., Long Beach, CA). They were 

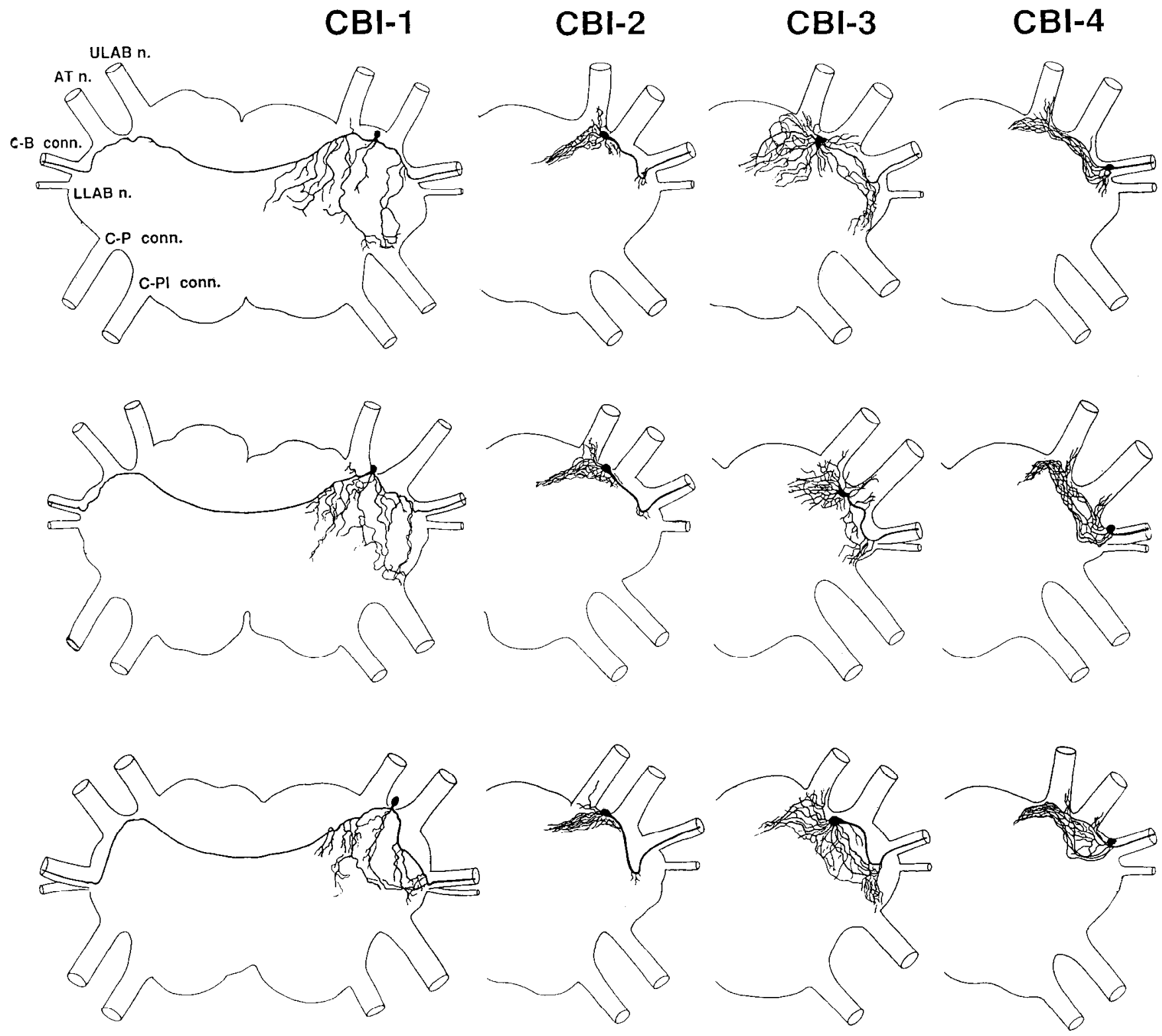

$1.0 \mathrm{~mm}$

Figure 3. Drawings of the somata and processes of CBIs that were filled with 5(6)-carboxyfluorescein dye and viewed live with a fluorescence microscope. Three typical examples of each CBI are shown. For abbreviations, see Figure 2.

maintained at $14-16^{\circ} \mathrm{C}$ in holding tanks containing aerated, filtered artificial seawater (ASW). Isolated ganglia preparations were most often utilized, but as specified, a number of experiments were also conducted with reduced preparations. Animals were initially anesthetized by injection of isotonic $\mathrm{MgCl}_{2}(50 \%$ of body weight) and dissected. In isolated ganglia preparations, the buccal and cerebral ganglia were removed with the C-B connectives intact. The connective tissue sheaths overlying the ganglia were surgically removed. The cerebral ganglion was pinned to the floor of the recording chamber, ventral side up. The buccal ganglion was pinned with the rostral surface up. In reduced preparations, such as those concerned with the sensory inputs and motor outputs of central neurons, the structures of the head innervated by the upper labial (ULAB), anterior tentacular (AT), and lower labial (LLAB) nerves, including the tentacles, lips, jaws, perioral zone, and related structures, were removed with the cerebral and buccal ganglia (Fig. 1). The anterior aorta was cannulated, and ASW was pumped into the arterial system to perfuse the tissue and to simulate the normal hydroskeleton of the animal. In other experiments, concerned with connections of the cerebral ganglion to the buccal mass, the buccal mass was dissected with all buccal ganglion nerves intact. Finally, for experiments in which it was necessary to identify buccal motor neurons B15 and B16, the buccal mass was dissected in order to isolate the accessory radula closer (ARC) muscle and its exclusive efferent innervation provided by neurons B 15 and B16 (Cohen et al., 1978).

Recording apparatus. Intracellular recordings were obtained from isolated ganglia or from reduced preparations maintained at room temperature $\left(21-23^{\circ} \mathrm{C}\right)$, in a clear Lucite recording chamber that was divided into three compartments, each containing ASW (Fig. 1). Each compartment had a clear Sylgard silicon elastomer floor with a thickness of 4-10 $\mathrm{mm}$ that was appropriate for the thickness of the different portions of the preparation. The first compartment was modified to hold the dissected tentacles, lips, and jaws. It contained an inflow port for arterial perfusion, a bubble separator to prevent air embolisms, and a perfusion outflow that was used to control the fluid level in the chamber. The 
compartment also permitted applications of mechanical or chemical stimuli. Seaweed stimuli consisted of seaweed extract (Susswein et al., 1978) or a piece of moistened, dried seaweed (Laver, Vega Trading Co., NY) presented by a hand-held forceps. Tactile stimuli were provided by a fire-polished Pasteur pipette or a flexible hair (von Frey hair). The second compartment contained the central ganglia. The walls separating it from the first and third compartments contained fine grooves that permitted passage of the peripheral nerves and connectives. The grooves were filled with Vaseline to maintain a watertight seal between compartments. The second compartment could also be subdivided into two sealed subcompartments that isolated the cerebral from the buccal ganglion with the C-B connectives intact. The third compartment was similar to the first and contained the dissected buccal mass.

Electrophysiology. For intracellular recording and stimulation, neurons were impaled with double-barreled microelectrodes that were made of thin-walled glass and contained $2 \mathrm{~m}$ potassium acetate. The electrodes were beveled so that their impedances ranged from 10 to $15 \mathrm{M} \Omega$. For the purposes of identifying cells and examining their morphologies, the potassium acetate in the stimulating electrode was replaced by a $3 \%$ solution of $5(6)$-carboxyfluorescein dye (Kodak) in $0.1 \mathrm{M}$ potassium citrate, titrated to $\mathrm{pH} 8.0$ with $\mathrm{KOH}$ (after Rao et al., 1986). These electrodes were beveled so that the impedance of the electrode containing the dye was $18-22 \mathrm{M} \Omega$ and the impedance of the potassium acetate electrode was 8-12 M $\Omega$. In other experiments, aimed at obtaining accurate measurements of the resting potentials of identified cells, the electrodes were filled with $2 \mathrm{M}$ potassium chloride and beveled so that their impedances were again between 10 and $15 \mathrm{M} \Omega$. Up to four simultaneous intracellular recordings were obtained using conventional electrometers. Nerve recordings were made with polyethylene suction electrodes and AC amplifiers.

Morphology. The locations, sizes, and shapes of cerebral neurons with axons in the C-B connectives were first determined by backfilling the connectives with cobalt or nickel chloride followed by treatment with rubcanic acid (Quicke and Brace, 1979). At the termination of many electrophysiological experiments, selected neurons were injected with 5(6)-carboxyfluorescein dye. To reduce the active transport of the dye from the cells, probenecid ( $10 \mathrm{~mm}$ final concentration) was added to the ASW bathing medium (Steinberg et al., 1987) and the preparation was kept for $8-24 \mathrm{hr}$ at $4^{\circ} \mathrm{C}$. The use of probenecid resulted in a dramatic improvement of the dye fills, particularly of small processes far from the cell body. A $1 \mathrm{M}$ aqueous solution of probenecid was prepared by dissolving the probenecid in a solution adjusted to $\mathrm{pH} 11$ by $\mathrm{NaOH}$. From this solution, a $100 \mathrm{~mm}$ stock solution was prepared and brought to $\mathrm{pH} 7-8$ by titration with $\mathrm{HCl}$. The living ganglia were cleared in $50 \%$ glycerol in ASW and viewed with a fluorescence microscope. Confirmation of cell morphology was made with Lucifer yellow injections (Stewart, 1978), followed by fixation in formalin, and clearing in methyl salicylate.

Histofluorescence. Dopamine-like histofluorescence was observed after the ganglia were fixed in $4 \%$ paraformaldehyde, $0.5 \%$ glutaraldehyde, and $30 \%$ sucrose in $0.1 \mathrm{~m}$ sodium phosphate buffer ( $\mathrm{pH} \mathrm{7.4)}$ for $12 \mathrm{hr}$ at room temperature (modified Faglu method of Furness et al., 1977 and Goldstein and Schwartz, 1989). A Leitz microscope was fit with filter pack D (excitation wavelengths, $355-425 \mathrm{~nm}$; viewing wavelengths, $>460 \mathrm{~nm}$ ) under which catecholamine fluorescence appears blue-green (Goldstein and Schwartz, 1989). In some preparations 3\% rhodamine-lissamine dye in water was iontophoretically ejected into cells that were identified by electrophysiological criteria prior to fixation. Identified dopamine-containing cells injected with the rhodamine appeared red when viewed with a $480 \mathrm{~nm}$ filter and blue-green with a 460 nm filter.

Identification of cerebral-to-buccal interneurons (CBIs). A number of criteria were used to identify individual interneurons that have their cell bodies in the cerebral ganglion and send their axons to the buccal ganglion (CBIs). Not all criteria were employed for every cell, but the properties of the CBIs we studied were sufficiently distinct that a few key criteria provided unambiguous identification of a CBI as a unique individual. A key criterion, used particularly in early experiments, was the presence of an axon in the ipsilateral $C$-B connective and the absence of axons in peripheral nerves. The presence of a CBI axon was indicated either by an antidromic spike that could be recorded from the soma of the CBI following electrical stimulation of the C-B connective, or independently by fluorescent microscopic observation of a dye-filled process in the C-B connective following dye injection into the soma. A second and major identification criterion of CBIs was the nature of the
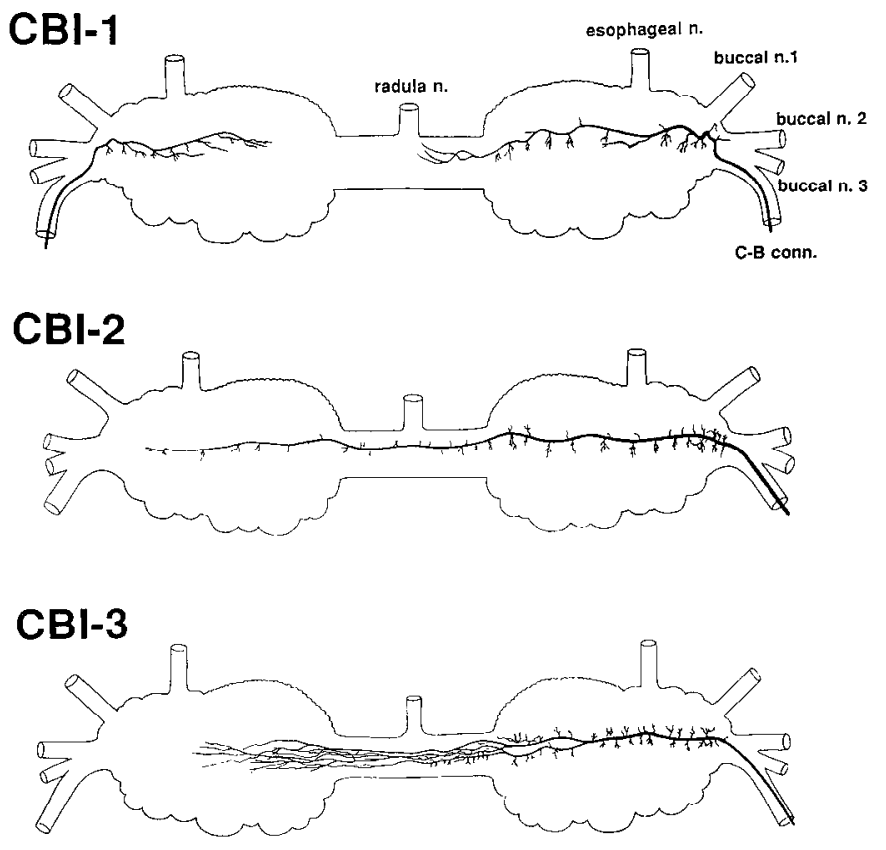

\section{CBI-4}

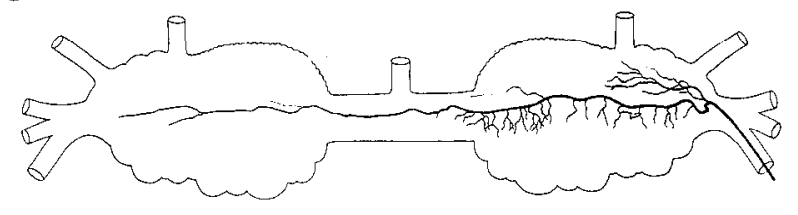

Figure 4. Drawings of CBI axon projections in the buccal ganglion. CBI-1 (top) projects two axons, one in each of the C-B connectives. The axons do not cross the buccal commissure. Each of the other CBIs projects a single main axon into the ipsilateral C-B connective that traverses the ipsilateral buccal hemi-ganglion, crosses the buccal commissure, and innervates the contralateral buccal hemi-ganglion. $n$., nerve; conn., connective.

characteristic postsynaptic potentials (PSPs) each of them evoked in identified buccal neurons B4 and B5 (Gardner and Kandel, 1977), cells that have a combined sensory, motor, and interneuronal function (Gardner and Kandel, 1977; Rosen et al., 1979; Fiore and Geppetti, 1981; Jahan-Parwar et al., 1983). As far as is known, the synaptic input of these cells is identical, so they will sometimes be referred to as B4/B5. Third, CBIs were distinguished by the characteristic pattern of bursting activity each produced among identified motor neurons in the buccal ganglion. Finally, the CBIs were identified by their distinctive locations and the characteristic shapes of their somata and dendritic fields.

\section{Results}

The cerebral ganglion contains three groups of neurons that send axons to the buccal ganglion via the $C-B$ connectives

The locations of the somata of neurons in the cerebral ganglion that send axons to the buccal ganglion were determined by backfilling the $\mathrm{C}-\mathrm{B}$ connectives with $\mathrm{Ni}^{2+}$ and $\mathrm{Co}^{2+}$ and developing the stains with rubeanic acid $(n=4)$. This method reliably revealcd the presence of approximatcly 20 ncurons in cach ccrebral hemi-ganglion, the majority of which were found on the ventral surface of the ganglion (Fig. 2). The cells form three groups: an anterolateral group that includes the previously identified serotonergic metacerebral cells (MCCs) (Weiss and Kupfermann, 1976; Weiss et al., 1978) and neurons within the identified M-cluster (see Ono and McCaman, 1980), a lateral group 
A
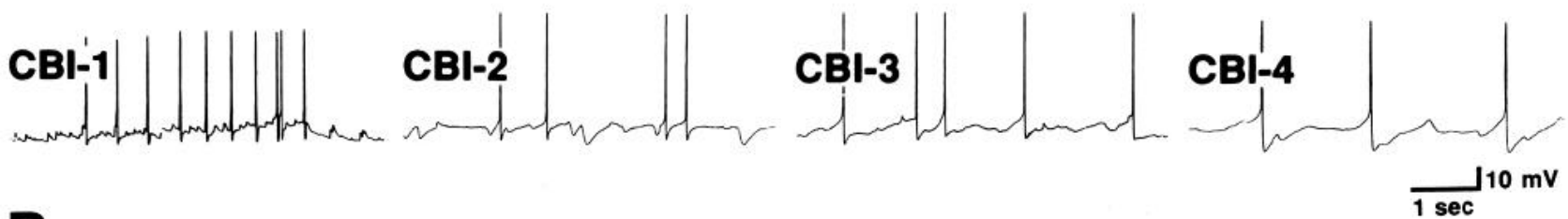

B
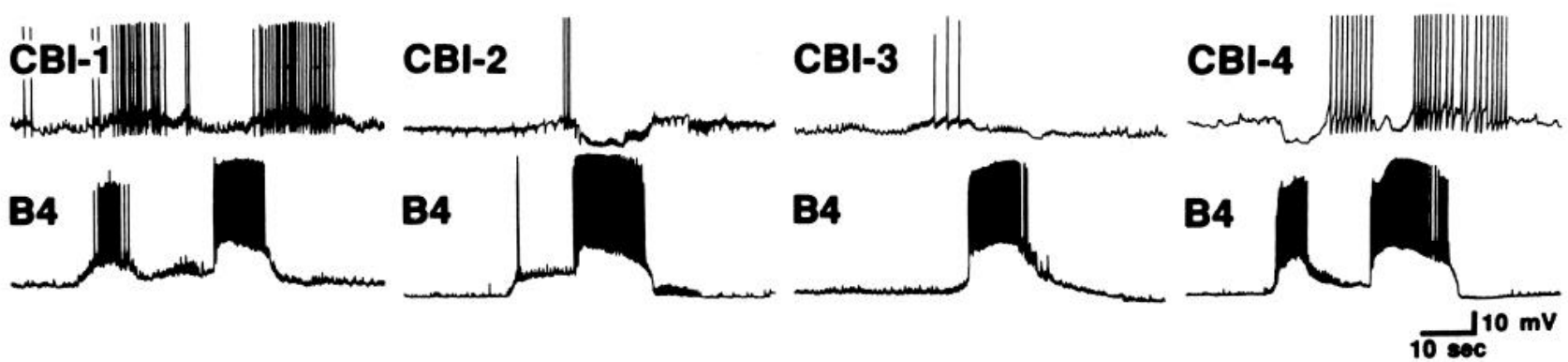

Figure 5. Spontaneous activity of CBIs was recorded in preparations that consisted of the isolated cerebral and buccal ganglia. $A$, Spontaneous fast synaptic inputs to $C B I-1, C B I-2, C B I-3$, and $C B I-4$ aperiodically gave rise to action potentials. $B$ (paired traces), Spontaneous slow synaptic inputs drove bursts of spikes that were correlated with activity that was recorded from identified buccal multiaction interneuron $B 4$, as well as from numerous other cerebral and buccal cells.

that consists of cells that surround the origin of the C-B connective and are constituents of the E-cluster (Jahan-Parwar and Fredman, 1976; McCaman and Weinreich, 1985), and a posterior group consisting of six to eight interganglionic cerebralto-buccal mechanoafferent (ICBM) neurons that are contained in the J and K cell clusters (Rosen et al., 1979, 1982). This report will focus upon three cerebral-to-buccal interneurons (CBI$1, \mathrm{CBI}-2$, and CBI-3) located in the M-cluster of the anterolateral group, and one neuron (CBI-4) located in the E-cluster of the lateral group (Fig. 2).

The M-cluster is made of up 6-10 cells that are tucked between the origins of the ULAB and AT nerves. The most prominent cells are two recently identified motor neurons ( $\mathrm{C} 11$ and $\mathrm{C} 12)$ that innervate the inner lips via axons in the LLAB nerve (Rosen, Halvorsen, Cropper, Miller, Weiss, and Kupfermann, unpublished observations; see also Ono and McCaman, 1980; McCaman and Weinreich, 1985). These are lightly pigmented cells that have diameters of $100 \mu \mathrm{m}$ or more in $300 \mathrm{gm}$ animals. CBI- 1 and CBI-2 are smaller, clear cells (40-60 $\mu$ m diameters), found medial and subjacent to $\mathrm{C} 11$ and $\mathrm{C} 12$. CBI-3 is a clear, superficial cell that is similar in size to CBI- 1 and CBI-2 and is located more posteriorly and medially. The E-cluster neuron CBI-4 is located at the anterior, ventral edge of the origin of the C-B connective and has a soma diameter of $30-50 \mu \mathrm{m}$. Each $\mathrm{CBI}$ has a homolog in the contralateral cerebral hemi-ganglion.

The CBls can be distinguished on the basis of morphological and electrophysiologic characteristcs

The morphology of the CBIs was determined by filling the neurons with either $5(6)$-carboxyfluorescein $(n=62)$ or Lucifer yellow fluorescent dye $(n=12)$ after the cells were positively identified by electrophysiological criteria. Whole-mounts of living or fixed ganglia were viewed with a fluorescence microscope. Figure 3 shows drawings of identified CBIs that were filled with 5(6)-carboxyfluorescein dye. Three examples of each type that were found in the left cerebral hemi-ganglion are shown in order to illustrate cell-to-cell similarities and differences.

The most prominent characteristic of CBI- 1 was the two main axons that arose from its cell body (Fig. 3, CBI-1). One axon entered the ipsilateral C-B connective and innervated the ipsilateral buccal hemi-ganglion (Fig. 4, CBI-1). The other crossed to the contralateral M-cluster, via the cerebral commissure, entered the contralateral C-B connective, and innervated the contralateral buccal hemi-ganglion. Within the ipsilateral cerebral hemi-ganglion, each CBI-1 axon periodically gave rise to three or more main branches that projected posteriorly into the central

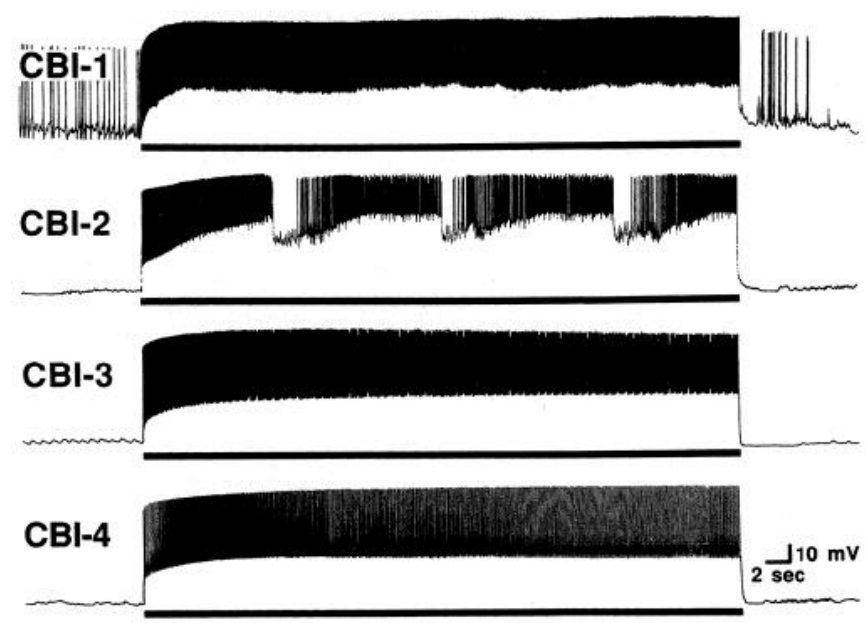

Figure 6. Responses of $C B I-1, C B I-2, C B I-3$, and $C B I-4$ to intracellular injection of a depolarizing, constant-current pulse. Horizontal lines indicate the period of current injection for each cell. With the exception of $C B I-3$, the firing of the CBIs evoked patterned bursting in the buccal ganglion. Only the phasic bursting of $C B I-2$ reflected the buccal activity that was evoked under the conditions of the experiment. 


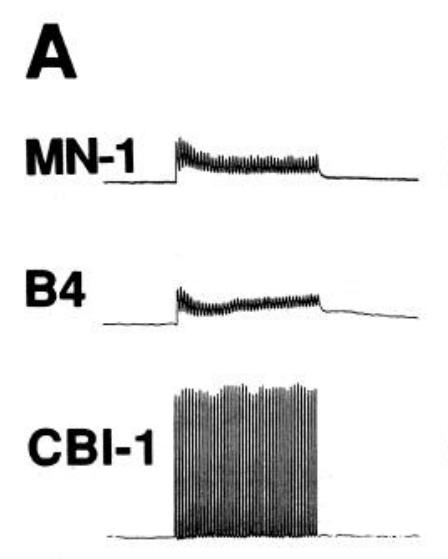

\section{B}

\section{C}

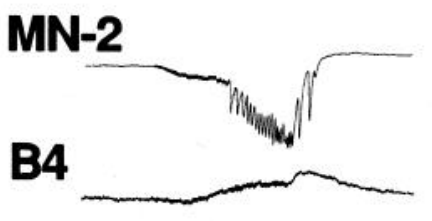

B15

B4

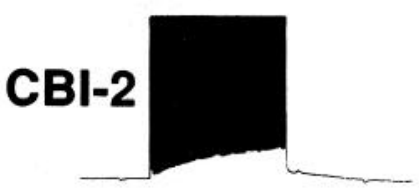

D
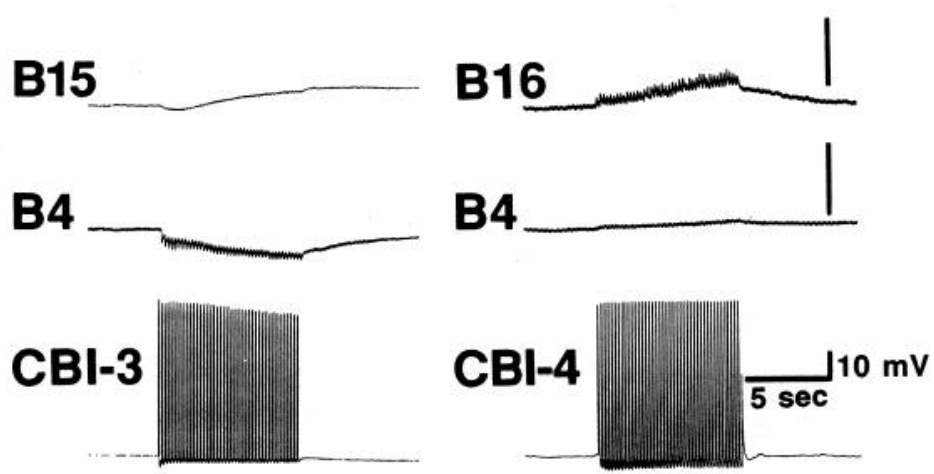

Figure 7. Putative monosynaptic connections of CBIs used to aid in their identification. $A$, Repetitive firing of $C B I-1$ spikes with a train of 20 msec intracellular current pulses produced fast, summating EPSPs in identified neuron $B 4$ and in $M N-1$, an unidentified neuron in the ventral motor neuron cluster of the buccal ganglion. The EPSPs followed at high rates ( $>20 \mathrm{~Hz}$; not shown) when the isolated cerebral and buccal ganglia were bathed in high-divalent-cation ASW $\left(2 \times\right.$ normal $\mathrm{Mg}^{2+}, 5 \times$ normal $\left.\mathrm{Ca}^{2+}\right)$. B, High rates of repetitive firing of $C B I-2$ produced a complex, slow EPSP in neuron $B 4$ and a slow IPSP in motor neuron $M N-2$. The responses were abolished when the ganglion remained in high-divalentcation ASW for periods exceeding $5 \mathrm{~min}$. $C$, Repetitive firing of $C B I-3$ produced summating IPSPs in neuron $B 4$ and a complex I/E PSP in motor neuron $B 15$. The responses persisted in high-divalent-cation ASW. $D, C B I-4$ evoked little or no PSP in neuron $B 4$ when the ganglia were bathed in normal ASW or in high-divalent-cation ASW. CBI-4 did, however, evoke summating fast EPSPs in identified ARC buccal motor neuron $B 16$.

region of the neuropil. These, in turn, ramified into finer processes.

In contrast to $\mathrm{CBI}-1, \mathrm{CBI}-2$ possessed only a single main axon (Fig. 3, CBI-2) that projected via the ipsilateral C-B connective into the neuropil of the ipsilateral buccal hemi-ganglion and then through the buccal commissure to the neuropil of the contralateral buccal hemi-ganglion (Fig. 4, CBI-2). The CBI-2 soma also gave rise to a number of short, thin processes that ramified extensively into a network of very fine processes that formed a halo around the cell body and also extended to the origin of the ULAB nerve.

The morphology of CBI-3 resembled that of CBI-2 except that the soma was located away from the anterolateral edge of the cerebral ganglion and its finer dendritic processes radiated from the soma in a more symmetrical fashion (Fig. 3, CBI-3). Furthermore, there was more extensive branching of the CBI-3 axon in the region of neuropil near the cerebral E-cluster (origin of the C-B connective), in the buccal commissure, and in the neuropil of the contralateral buccal hemi-ganglion (Fig. 4, CBI3). CBI-4 was found in the cerebral E-cluster (Fig. 3, CBI-4). Its soma was located adjacent to the anterior edge of the origin of the C-B connective. Like CBI-2 and CBI-3, CBI-4 projected a main axon in the ipsilateral $\mathrm{C}$-B connective that innervated both the ipsilateral and contralateral buccal hemi-ganglia (Fig. 4 , CBI-4). CBI-4 projected a number of dendritic processes anteromedially toward the origins of the ULAB and AT cerebral nerves, where they ramified into a fine network similar to that of CBI-2. The morphologies of CBI-1 -4 were sufficiently distinct so as to distinguish reliably one from the others. However, several unidentified cells with similar morphologies were also found in the anterolateral region of the cerebral ganglion, so that positive CBI identification required both morphological and electrophysiological criteria.

Each of the CBIs has distinctive electrophysiological properties, but they also share certain common features. In isolated ganglia or reduced preparations, they were all generally silent cells that received spontaneous EPSPs and IPSPs. Occasionally the spontaneous EPSPs exceeded threshold for action potentials (Fig. 5A). The most distinctive feature of the spontaneous spike activity of all the CBIs was that at the times that the buccal ganglion generated coordinated patterns of spontaneous burst activity, the CBIs always exhibited bursts of spikes that were in phase with the buccal ganglion bursts (Fig. $5 B$ ). These spontaneous bursts of buccal ganglion activity were similar to "pattern 2 " bursts described by Susswein and Byrne (1988) and could be seen in many types of buccal cells, including identified neurons B4 and B5 (Fig. 5B, bottom). The spontaneous buccal ganglion bursts as reflected in the activity of B4 and B5 had variable amounts of low- and high-frequency components, but each of the CBIs consistently showed a characteristic pattern of excitation and inhibition during the high-frequency component. Spontaneous phasic bursting was also observed in cerebral cells other than the CBIs, and many of these were located close to the CBIs (e.g., lip motor neurons $\mathrm{C} 11$ and $\mathrm{C} 12$ ). Mean resting potentials, action potential amplitudes, and spike durations were similar, but not identical, for the CBIs (data summarized in Table 1). In particular, CBI-1 has a larger and faster spike than the other cells.

\begin{tabular}{|c|c|c|c|}
\hline Neuron & $\begin{array}{l}\mathrm{RP} \\
(\mathrm{mV})\end{array}$ & $\begin{array}{l}\text { AP amplitude } \\
(\mathrm{mV})\end{array}$ & $\begin{array}{l}\text { AP duration } \\
\text { (msec) }\end{array}$ \\
\hline CBI-1 & $\begin{array}{l}47.88 \pm 3.44 \\
n=8\end{array}$ & $\begin{array}{l}77.75 \pm 5.06 \\
n=8\end{array}$ & $\begin{array}{l}2.81 \pm 0.37 \\
n=8\end{array}$ \\
\hline CBI-2 & $\begin{array}{l}48.40 \pm 4.58 \\
n=10\end{array}$ & $\begin{array}{l}62.50 \pm 10.04 \\
n=10\end{array}$ & $\begin{array}{l}5.30 \pm 1.09 \\
n=10\end{array}$ \\
\hline CBI-3 & $\begin{array}{l}47.40 \pm 4.65 \\
n=10\end{array}$ & $\begin{array}{l}61.80 \pm 5.77 \\
n=10\end{array}$ & $\begin{array}{l}6.45 \pm 0.83 \\
n=10\end{array}$ \\
\hline CBI-4 & $\begin{array}{l}44.38 \pm 5.34 \\
n=8\end{array}$ & $\begin{array}{l}68.50 \pm 9.43 \\
n=8\end{array}$ & $\begin{array}{l}5.13 \pm 0.58 \\
n=8\end{array}$ \\
\hline
\end{tabular}

$\overline{\text { Data are expressed as means } \pm \mathrm{SD} ; n=\text { number of cells sampled. RP, resting }}$ potential; AP, action potential. 


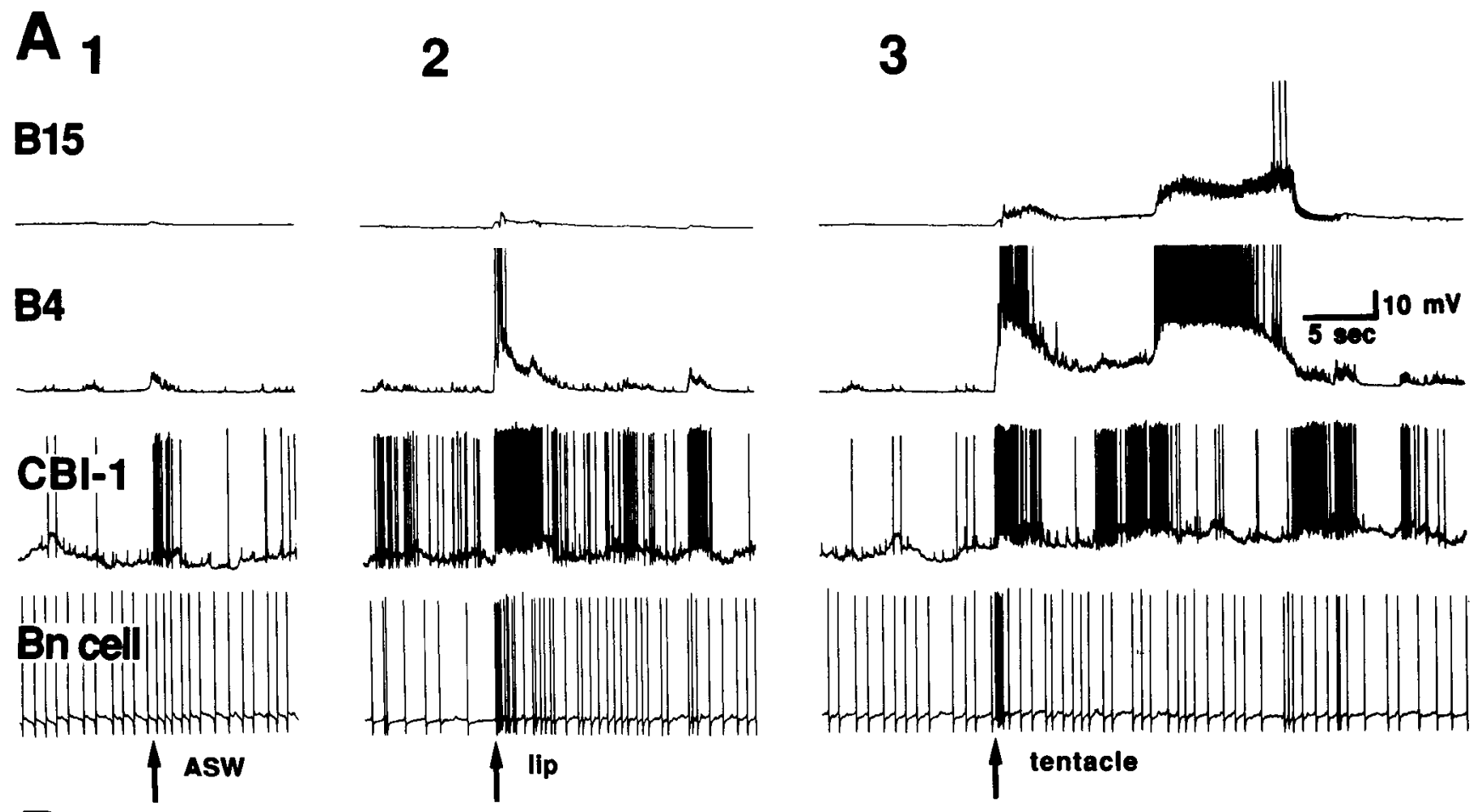

B

B16

$\mathbf{B 4}$

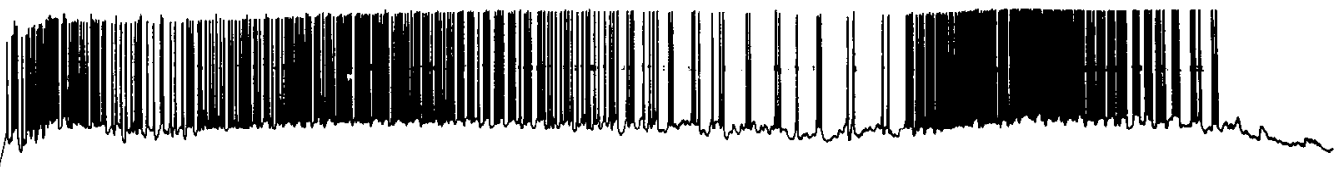

CBI-3

1 esc

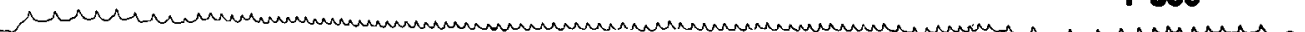

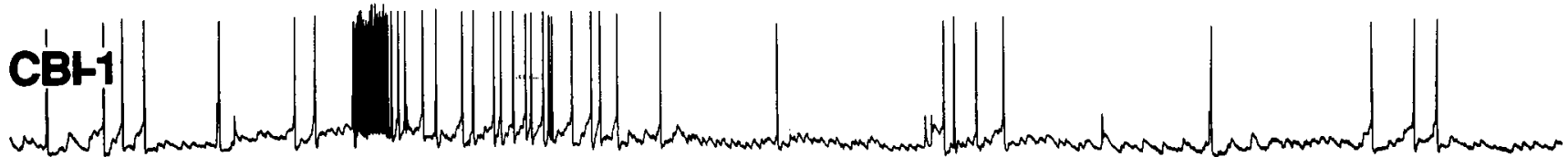

radula

Figure 8. Responses of $C B I-1$ to brief, tactile stimuli applied to the tentacles, lips, and buccal mass of $A$ plysia. Control recordings were made of the responses of a $B n$ cell in the ipsilateral cerebral B-cluster and of the responses of identificd buccal cells $B 4$ and $B 15$. A1, Gentle stirring of the seawater adjacent to the ipsilateral tentacle tip (at arrow) was sufficient to evoke a burst of spikes in $C B I-1$ and increase the rate of $B n$ cell spiking. $A 2$, Brief $(50 \mathrm{msec})$ application of a $1 \mathrm{gm}$ von Frey hair $(0.5 \mathrm{~mm}$ diameter) to the lips evoked a burst of spikes in cells $C B I-1, B n$, and $B 4$. $A 3, \mathrm{~A}$ similar stimulus delivered to the anterior edge of the ipsilateral tentacle evoked a short-latency burst of spikes followed by a longer-latency burst of coordinated spiking recorded from all the neurons. $B$, In an isolated cerebral and buccal ganglia preparation that included the ARC muscle and its innervation via buccal nerve 3, brief touch of the radula membrane at the site of insertion of the ARC muscle was capable of evoking a burst of $C B I-1$ spikes and a burst of EPSPs in CBI-3, and a cycle of coordinated bursting from buccal neurons $B 4$ and $B 16$.

The CBIs differ in four important electrophysiological properties that were used to distinguish the cells: (1) the character of spontaneous inputs, (2) the response of the cells to maintained depolarization, (3) the nature of synaptic outputs to identified cells, and (4) their ability to drive BMPs. For example, spontaneous inputs to CBI- 1 consisted predominantly of fast EPSPs (Fig. 5A, CBI-1), whereas CBI-2 received predominantly inhibitory spontaneous inputs (Fig. $5 A$, CBI-2) and CBI-3 received 
inputs that consisted of a mixture of EPSPs and IPSPs (Fig. $5 A$, CBI-3). CBI-4 received a characteristic, spontaneous, slow EPSP (Fig. 5A, CBI-4). Intracellular stimulation of CBI-1, CBI-3, and CBI-4 with maintained constant currents produced tonic firing (Fig. 6), whereas CBI-2 fired in bursts that were phase-locked to bursting activity elicited in the buccal ganglion (Fig. 6, CBI2). The firing of both CBI-1 and CBI-4 shown in Figure 6 elicited one or more cycles of bursting activity recorded in the buccal ganglion (see sections below), but this activity was not reflected in the response of the CBIs to the maintained depolarization. Examples of the distinctive synaptic outputs of the CBIs are shown in Figure 7. For the purposes of this article, PSPs that followed, one-for-one, high rates of firing of the presynaptic neuron in the presence of a high-divalent-cation solution were classified as monosynaptic, although it is recognized that this criterion is not infallible. Firing of CBI-1 produced fast, monosynaptic EPSPs in identified buccal neuron B4 and its twin, neuron $\mathrm{B} 5$ (Fig. 7A, B4), firing of CBI-2 produced a complex, slow, polysynaptic EPSP in neurons B4 and B5 (Fig. 7B, B4), and firing of CBI-3 produced complex, fast and slow, monosynaptic IPSPs in neurons B4 and B5 (Fig. 7C, B4). Only CBI-4 failed to produce reliable PSPs in neurons B4 and B5. However, CBI- 4 could be recognized by its unique location and by the fast, monosynaptic EPSP it produced in identified buccal motor neuron B16, which is different from PSPs produced in neuron B1 6 by the other CBIs (Fig. 7D, B16). The finding that each of the CBIs produced markedly different PSPs in identified buccal neurons B4 and B5 was routinely used to aid in their identification. Each of the CBIs was also capable of producing different types of PSPs in different neurons comprising the ventral motor neuron cluster of the buccal ganglion (see examples in Fig. 7A$C$, top).

The most striking difference between the CBIs was their capacity to elicit patterned bursting activity of cells in the buccal ganglion. In rested preparations, continuous firing of CBI-1 usually produced a single cycle of coordinated bursting activity of cells in the buccal ganglion (see Figs. 10, 11; see also the discussion of the nature of the single cycle in the following section), whereas when CBI-2 or CBI-4 was fired with a constant depolarizing current, they initiated and sustained a rhythmic pattern of coordinated bursting activity among buccal cells (e.g., Figs. 16, 27), but the details of the elicited programs differed

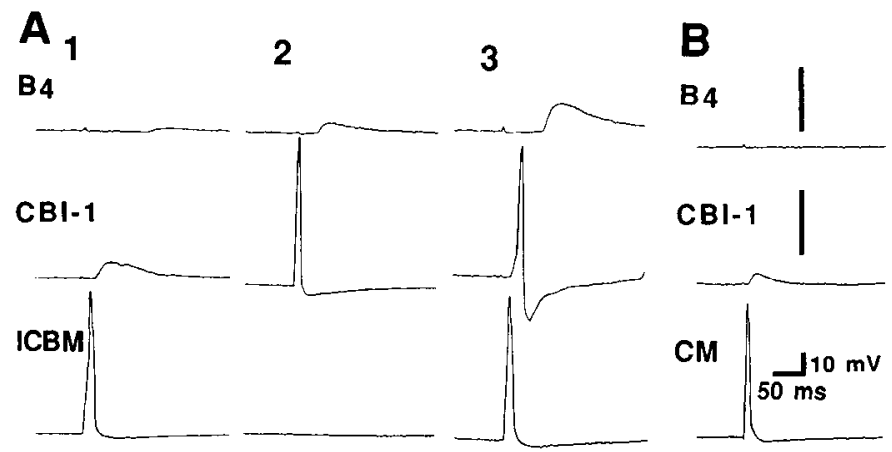

Figure 9. Cerebral mechanoafferent neurons (ICBM and $C M$ ) make monosynaptic connections to CBI-1. AI, An ICBM neuron in the cerebral J-cluster was identified by the EPSP it produced in buccal neuron B4. In high-divalent-cation ASW ( $3 \times$ normal $\mathrm{Mg}^{2+}, 3 \times$ normal $\left.\mathrm{Ca}^{2+}\right)$, intracellular stimulation of the $I C B M$ neuron, sufficient to elicit a single action potential spike, evoked an EPSP in the ipsilateral $B 4$ cell and also in the ipsilateral $C B I-1 . A 2$, The $C B I-I$ was similarly identified by the EPSP it croked in the same $B 4$. $A 3$, In a rested preparation, stimulation of the $I C B M$ evoked an EPSP in $C B I-1$ that was sufficient to trigger a $C B I-1$ spike. The resulting EPSPs evoked in neuron $B 4$ exhibited temporal summation. $B$, A J-cluster $C M$ neuron, which was not an ICBM by virtue of the fact that it did not evoke an EPSP in neuron $B 4$, evoked a monosynaptic EPSP in neuron $C B I-1$. Vertical calibration bars, $10 \mathrm{mV}$.

for the two cells. CBI-3 was generally incapable of driving coordinated bursting activity (e.g., Fig. 23), but a motor program occasionally developed (e.g., Fig. $24 A$ ) during a long period of stimulation at a moderate rate of firing (e.g., $7.5 \mathrm{~Hz}$ ). Details of the distinguishing features of the CBIs are discussed in subsequent sections, which deal with each CBI in turn.

On occasion, cells in the M- or E-clusters were encountered that had axons in the C-B connective (as determined by dye fills) but did not have the properties of the four identified CBIs. One such cell in the M-cluster was similar to CBI-3 in that it did not drive a buccal program, but unlike CBI-3 it did not exert synaptic actions on buccal neurons B4 and B5. It produced short-latency synaptic actions on other cells in the buccal ganglion. Another CBI was encountered in the E-cluster. Firing of this cell evoked a BMP, but unlike CBI-4, which is also in the E-cluster, the neuron fired in a highly phasic manner while the program it elicited was in progrcss. This ccll was hard to impale

Table 2. Synaptic connections between CBIs and identified cells in the buccal and cerebral ganglia

\begin{tabular}{lllll}
$\begin{array}{l}\text { Buccal } \\
\text { neuron }\end{array}$ & CBI-1 & CBI-2 & CBI-3 & CBI-4 \\
\hline B1 & poly-i & poly-i & unknown & unknown \\
B2 & poly-i & poly-i & unknown & unknown \\
B4 & mono-e fast & poly-e slow & mono-i fast & no resp. \\
B5 & mono-e fast & poly-e slow & mono-i fast & no resp. \\
B15 & mono-i/e fast & poly-i/e slow & mono-i/e slow & no resp. \\
B16 & mono-e fast & poly-e/i slow & mono-e slow & mono-e fast \\
B31/B32 & poly-e & mono-e fast & poly-e & unknown \\
C11 & no resp. & mono-e fast & no resp. & no resp. \\
C12 & no resp. & no resp. & no resp. & no resp. \\
\hline
\end{tabular}

Abbreviations: e, EPSP; i, IPSP; i/e, complex, inhibitory-excitatory PSP; e/i, complex, excitatory-inhibitory PSP; mono presumed monosynaptic connection since the PSP persists in high-divalent-cation ASW solutions and follows, one for one, spikes in the presynaptic cell; poly, presumed indirect connection since the PSP does not persist in high-divalentcation ASW solutions and does not follow, one for one, spikes in the presynaptic cell; no resp., connection tested but not found to exist; unknown, connection not tested. 


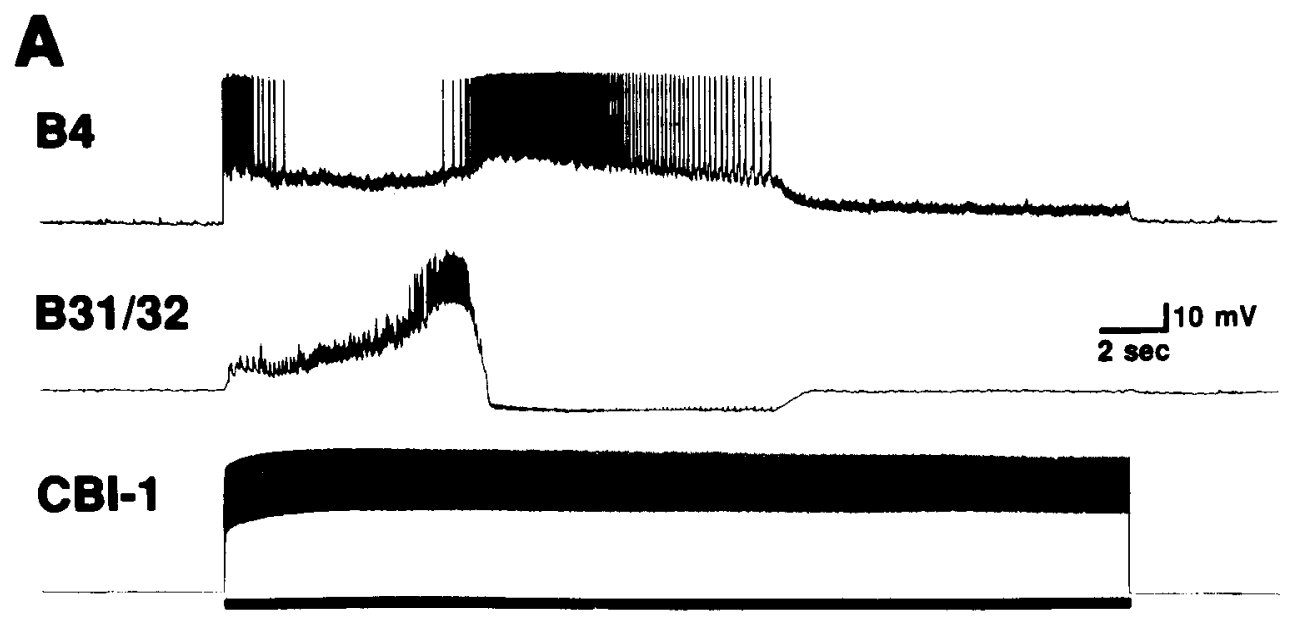

Figure 10. Tonic firing of $\mathrm{CBI}-\mathrm{I}$ evoked a single cycle of a motor program reflected in different identified cells. The results of three different preparations are shown, illustrating recordings from buccal premotor neuron $B 4$ and pattern-generating cells $B 31 / B 32$ $(A)$; buccal neuron $B 4$, motor neuron $B 15$, and the ipsilateral cerebral neuromodulatory neuron $M C C(B)$; and $\mathrm{BCI}$ $B 19, B 4$, and putative cerebral command element $C B I-2$, which shows a cycle of feedback inhibition $(C)$. In this and the following figures, when a cell was fired by depolarizing constant current, the cell is shown in the bottom trace and the stimulus duration is indicated by a thick horizontal line.
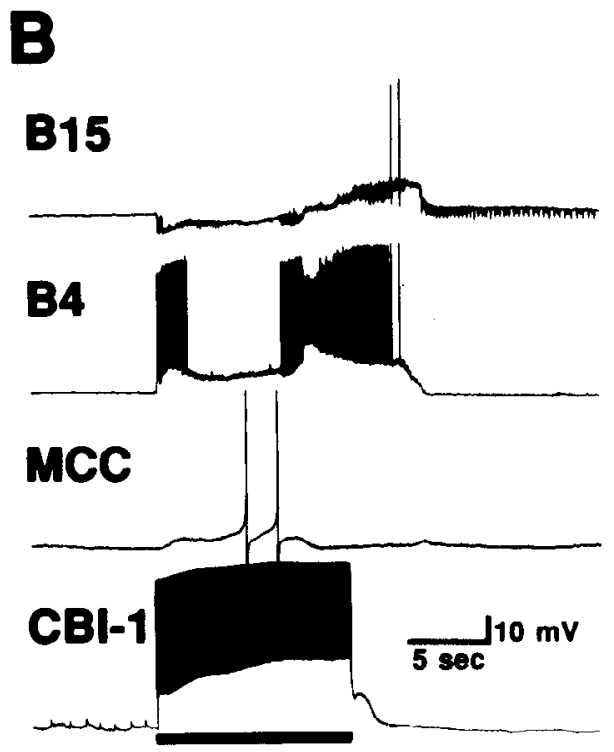

\section{C}
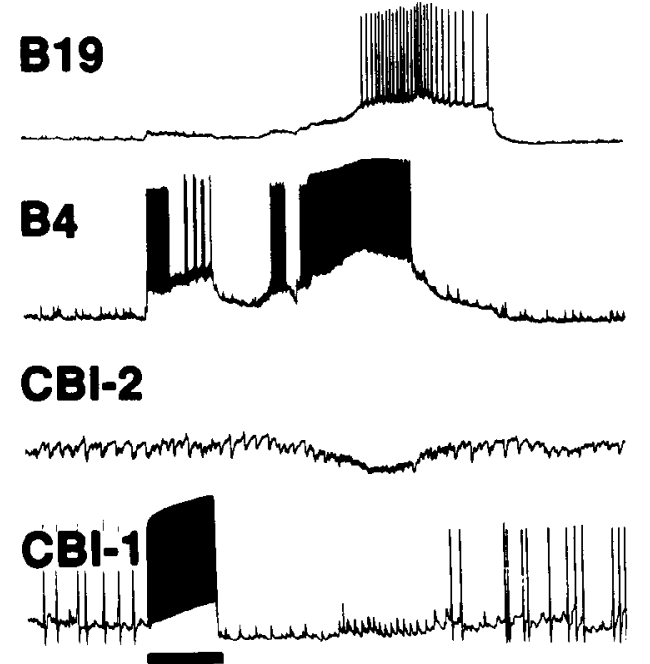

repeatedly and might have been better approached from the dorsal surface of the cerebral ganglion.

\section{CBI-1}

Sensory inputs to CBI-1. To characterize the CBIs, we determined their responses to tactile or chemosensory stimuli presented to the tentacles, lips, perioral zone, and buccal mass. In these experiments, the anterior aorta was perfused with ASW, so that the head structures were relaxed and inflated, as in an intact animal. The buccal ganglion (and also sometimes buccal mass) was present so that, unless otherwise noted, it was not possible to distinguish direct sensory responses from secondary responses associated with the triggering of motor programs in the buccal ganglion. Studies of the sensory input and of the outputs of CBI-1 suggest that this cell functions as a mechanosensory interneuron that modulates BMPs. Tactile stimuli (e.g., von Frey hairs) applied to any of the receptor surfaces of the head, including the buccal mass, produced powerful synaptic inputs and vigorous bursts of spikes in CBI-1 (Fig. 8). CBI-1 responds to strong as well weak stimuli with slowly adapting spike bursts. Its threshold for firing to tactile stimuli applied to the anterior tentacles is similar to that of the cerebral Bn cells, which are highly sensitive to mechanostimulation of the skin (Fredman and Jahan-Parwar, 1980; Teyke et al., 1989) and can fire in response to gentle stirring of the ASW bath (Fig. 8Al). In addition to firing in response to gentle touch of the lips, tentacles (Fig. 8A2,A3), and surfaces of the buccal cavity, CBI-1 was found to respond to touch of the part of the radula membrane at the site of attachment of the ARC muscle (Fig. 8B). The sensory input was present when all nerves were severed except for buccal nerve 3, which innervates the ARC muscle (Cohen et al., 1978).

Applications of chemical stimuli to the dissected head preparation, including graded concentrations of seaweed extract and $4 \mathrm{M} \mathrm{NaCl}$, also produced vigorous excitatory responses in CBI1. These, however, were generally associated with movements of the peripheral tissues, consisting of local deformations of the skin and withdrawal responses involving the underlying body wall muscle. Careful applications of low concentrations of seaweed extract that were generally sufficient to arouse intact animals, but which did not elicit tentacular movements in the dissected preparation, failed to produce responses in CBI-1. The 

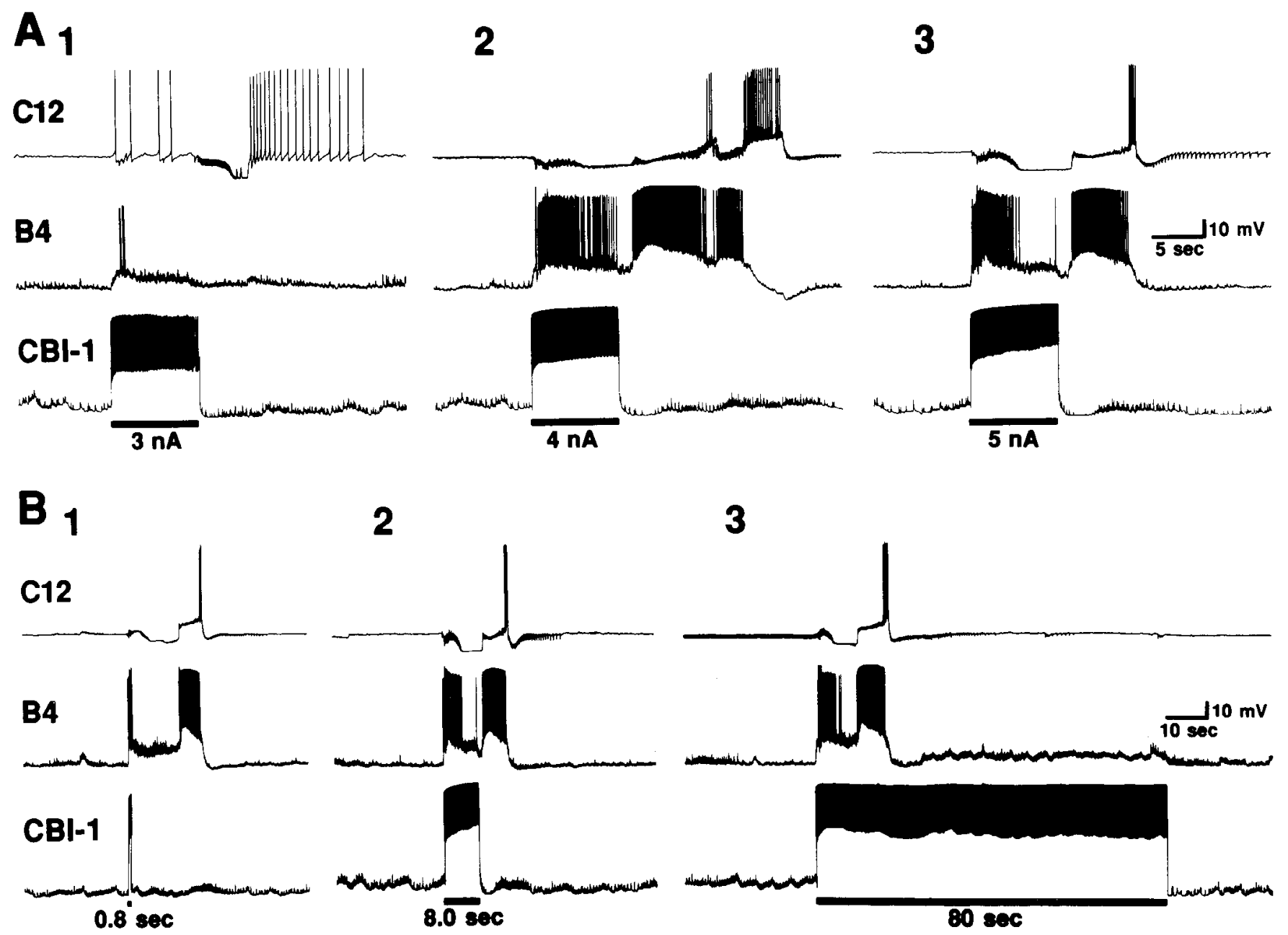

Figure 11. $\quad C B I-1$ triggered a single cycle of a motor program irrespective of variations in the strength $(A)$ and duration $(B)$ of the suprathreshold intracellular stimulus that elicited spikes in the cell. $A 1$, Just above threshold, an intracellular current pulse ( $3 \mathrm{nA}, 8$ sec duration) elicited a relatively low-frequency $(<17 \mathrm{~Hz})$ train of spikes in $C B I-1$ that evoked fast EPSPs in $B 4$ capable of firing a few spikes and a delayed series of polysynaptic inputs to a cerebral lip motor neuron (C12). $A 2$, Further above threshold, the stimulus ( $4 \mathrm{nA}, 8 \mathrm{sec}$ ) elicited a relatively high-frequency train of spikes $(>28 \mathrm{~Hz}$ ) that evoked a burst of summating EPSPs and spikes in $B 4$ and also triggered several cycles of a program that included the phasic activity of $B 4$ and the motor neuron $C 12$. $A 3$, At higher frequencies of activation ( $>50 \mathrm{~Hz}), C B I-1$ was still only capable of evoking a single cycle of a motor program incorporating cells in both the buccal and cerebral ganglia. $B 1$, At $5 \mathrm{nA}$ of stimulating current, a $0.8 \mathrm{sec}$ intracellular stimulus to $C B I-1$ was capable of eliciting a burst of spikes at a frequency sufficient to evoke a single cycle of a motor program. Increasing the duration of the intracellular stimulus to $8.0(B 2)$ and $80.0 \mathrm{sec}(B 3)$ caused longer bursts of high-frequency $C R I-l$ firing, but failed to increase the number of cycles of the program evoked by CBI-1.

latter observation suggested that CBI-1 might be responding to proprioceptive inputs. To test this possibility, we fired cerebral ganglion Bn neurons in order to produce tentacular withdrawal responses (Fredman and Jahan-Parwar, 1977; Teyke et al., 1989). The firing of Bn cells did not produce synaptic input to the CBI-1 neurons in isolated ganglion preparations. However, in the reduced preparations that included the tentacles, the firing of $\mathrm{Bn}$ cells produced pronounced activation of CBI-1. The latency of the CBI-1 response was long and variable and generally correlated with the development of observable tentacular movements.

Direct inputs of cerebral mechanoafferent neurons to CBI-1. The powerful mechanosensory responses of CBI-1 suggested that the cell might receive direct inputs from previously identified cerebral mechanoafferent (CM) neurons (Rosen et al., 1979), including the ICBM subclass of CM neurons that have both perioral zone and buccal mass receptive fields (Rosen et al.,
$1982,1989 a)$. This was further suggested by the fact that the firing of a single ICBM spike produced a single cycle of coordinated buccal bursting activity (Rosen et al., 1982) similar to that evoked by firing CBI-1 (see Fig. 11). In experiments in which the isolated cerebral and buccal ganglia were bathed in high-divalent-cation ASW, both ICBM and CBI-1 neurons were identified by the monosynaptic EPSPs they evoked in neuron B4 (Fig. 9A1, $A 2$ ). Intracellular stimulation of a single ICBM neuron sufficient to elicit a single spike evoked a unitary EPSP in both the ipsilateral CBI-1 and buccal cell B4 (Fig. 9A). The ICBM neurons produced monosynaptic EPSPs in both the ipsilateral and contralateral CBI- 1 neurons, which is consistent with the morphology of the ICBMs. Each ICBM, as well as each CBI-1, has bilateral axons in the region of both cerebral M-clusters and in both C-B connectives (Rosen et al., 1989a). The latency of the ICBM to B4 EPSP was four times that of the latency of the ICBM to CBI-1 EPSP, presumably because of the 


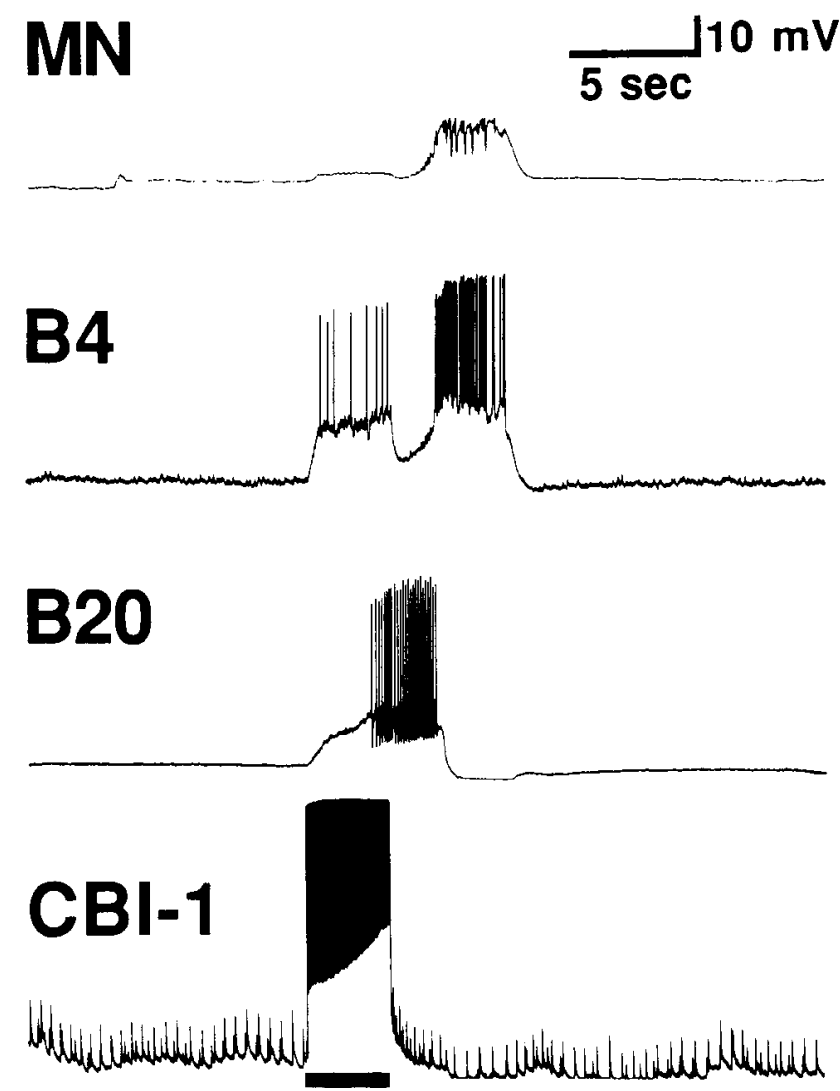

Figure 12. $C B I-1$ was found to provide excitatory input to $B 20$, an identified buccal cell that shows dopamine-like histofluorescence (see Rosen et al., 1989b; Teyke et al., unpublished observations) and that was found to drive a rhythmic BMP. CBI-1 inputs to $B 4$ and $M N$ (an unidentified ventral cluster motor neuron) are also shown. greater conduction time required for a spike originating in the cerebral ganglion to reach the buccal ganglion. When an ICBM was repeatedly fired, even at low frequency, the EPSPs it produced in B4 and CBI-1 decremented and failed to evoke spikes. In rested preparations, the firing of a single ICBM produced a short-latency EPSP in CBI- 1 of sufficient amplitude to evoke a spike (Fig. 9A3). The resulting spikes generated in each of these cclls, and presumably from the contralatcral CBI- 1 as well, produced summating EPSPs in neuron B4. The recruitment of CBI-1 cells by ICBM neurons might contribute to the ability of a single ICBM spike to trigger a coordinated burst pattern in the buccal ganglion (Rosen et al., 1982). Approximately $20 \%$ of the nonICBM CM neurons also produced unitary EPSPs in CBI-1, although they produced no direct input to B4 (Fig. 9B). Repetitive firing of these CM neurons produced constant-latency EPSPs that followed at high frequencies $(>20 / \mathrm{sec})$, suggesting that the connections were monosynaptic. Moreover, the EPSPs persisted and the latencies were unchanged when the cerebral and buccal ganglia were bathed in high-divalent-cation ASW.

Direct outputs of CBI-1 to follower cells in the buccal ganglion. CBI-1 was found to make direct, presumably monosynaptic, connections to a variety of types of identified buccal neurons in addition to connections to B4 already described (Fig. 9A2). Tablc 2 summarizes the conncctions that have becn most thoroughly examined. These include the direct connections to the ARC motor neurons B1 5 and B 16 (Weiss et al., 1978; Cropper et al., 1987, 1990) and the polysynaptic connections to the putative pattern-generating neurons B31 and B32 (Susswein and Byrne, 1988) and the peptidergic neurons (B1 and B2) that innervate the gut (Lloyd et al., 1988).

The BMP driven by CBI-1. Intracellular stimulation of CBI-1 with a maintained, depolarizing, constant-current pulse, sufficient to fire a train of spikes, evoked a single cycle of coordinated
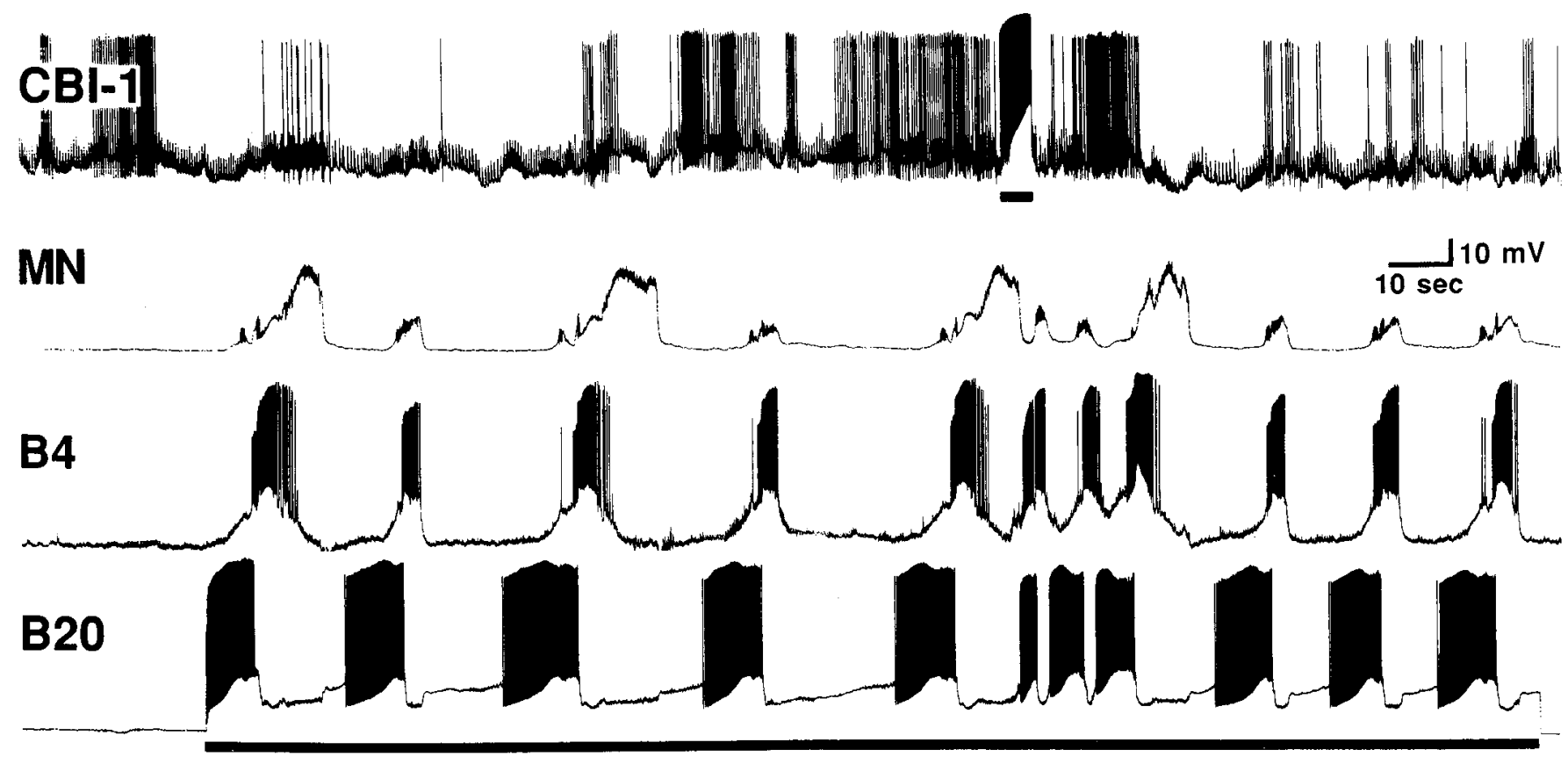

Figure 13. $C B I-1$ modulation of the B20-driven BMP. When B20 was intracellularly stimulated with maintained, constant current (horizontal line, bottom trace), it drove a program that included phasic activity of $C B I-1$. When $C B I-1$ was fired briefly during the ongoing program (horizontal line, top trace), the program phase advanced and showed an increase in overall frequency that outlasted the period of CBI-1 stimulation. The buccal program was monitored by recordings of $B 4$ and $M N$ (an unidentified ventral cluster motor neuron) activity. 
burst activity recorded from many types of buccal and cerebral cells (Fig. 10), regardless of the intensity or duration (above a threshold value) of the stimulus (Fig. 11A,B). The burst pattern was observed in 18 of 20 experiments when the preparation was rested for at least $5 \mathrm{~min}$ and the depolarizing intracellular stimulus was sufficient to elicit a $10 \mathrm{~Hz}$ or greater train of spikes (Fig. 11A2) for periods exceeding $0.5 \mathrm{sec}$ (Fig. 11B1). In 3 out of 20 preparations, firing of CBI-1 at higher frequencies, and for periods of up to $10 \mathrm{sec}$, evoked more than a single cycle of burst activity (e.g., Fig. 11A2). The typical burst pattern evoked by CBI-1 involved previously identified motor neurons (e.g., $\mathrm{B} 15, \mathrm{~B} 16)$, multiaction interneurons (B4/B5), and putative pattern-generating neurons (B31, B32), as well as neuromodulatory cells (e.g., MCCs) and a buccal-to-cerebral interneuron (BCI; B19) that provides feedback to the CBIs (Rosen, Weiss, and Kupfermann, unpublished observations). Figure $10 \mathrm{~A}$ illustrates the cycle of burst activity evoked in putative pattern-generating neuron B31/B32 and in multiaction neuron B4. The cycle of B4 activity showed two phases of spiking: one a short-latency, monosynaptic phase associated with the EPSPs evoked by CBI-1 on $\mathrm{B} 4$, and a second, polysynaptic phase that reflects activation of a CPG by CBI-1. The phases could be dissociated either by firing CBI-1 at a frequency just subthreshold for evoking the polysynaptic phase (Fig. 11Al) or by repeated firing at a suprathreshold frequency. In either case the initial monosynaptic phase persisted and the polysynaptic phase was abolished. The cycle of B31/B32 activity was always associated with the polysynaptic phase of B4 bursting and was an excellent predictor of its occurrence. Figure $10 B$ shows a cycle of coordinated activity evoked by CBI-1 in the ipsilateral MCC and in identified buccal motor neuron B15. The cycle of activity produced in neuron B15, like that produced in $\mathrm{B} 4$, reflects both a mono- and a polysynaptic input, whereas the input to the MCC reflects the polysynaptic activation of a buccal CPG that feeds back to the cerebral ganglion. Figure $10 C$ shows that the BMP activated by CBI- 1 incorporates the activity of a BCI (B19; Rosen, Weiss, and Kupfermann, unpublished observations), which contributes to the feedback inhibition and excitation recorded in CBI-2. Overall, the burst pattern recorded in B4 and B5 was identical to the previously described pattern that was elicited by firing single ICBM spikes in rested preparations (Rosen et al., 1982).

$C B I-1$ can modulate a BMP driven by $B 20$. We have recently shown that a BMP can be driven by a pair of bilaterally symmetrical, small buccal cells (B20s) that exhibit dopamine-like histofluorescence (Rosen et al., 1989b). The firing of CBI-1 produced excitation in these cells, as well as in B4 and in unidentified motor neurons (Fig. 12). When CBI-1 was fired briefly during the BMP driven by B20, the normal program cycling was phase-advanced and the cycling rate increased markedly for a cycle or two. Moreover, a more modest, but more enduring, increase in the baseline rate of patterned bursting was also observed (Fig. 13). The phenomenon was observed in each of three preparations in which B20 and CBI-1 were simultaneously impaled.

CBI-1 shows dopamine-like histofluorescence. When the cerebral and buccal ganglia were fixed by the formaldehyde-glutaraldehyde (Faglu) method (Furness et al., 1977; Goldstein and Schwartz, 1989), a number of cells in the cerebral ganglion showed catecholamine (blue-green) histofluorescence, indicative of dopamine (see also Tritt et al., 1983; Rathouz and Kirk, 1988; Goldstein and Schwartz, 1989). One small- to mid-sized neuron in each of the cerebral M-clusters was seen in each of
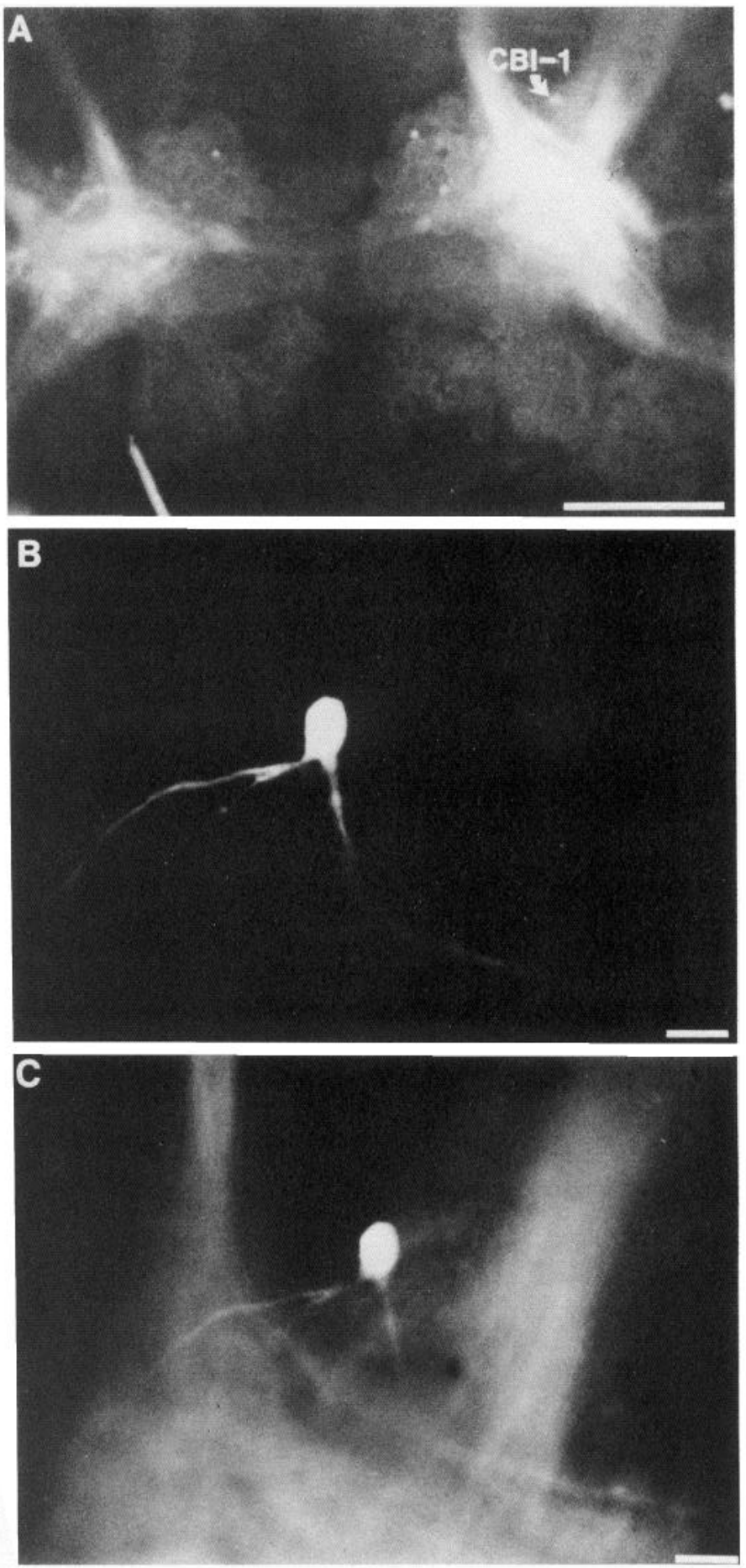

Figure 14. A, Low-power photomicrograph of the ventral surface of a cerebral ganglion that was fixed by the Faglu method and viewed with a fluorescence microscope. A single bilateral pair of cells in the M-clusters $(C B I-1 \mathrm{~s})$ showed dopamine-like histofluorescence. $B$, Highpower view of a CBI-1 that was identified by electrophysiological criteria and filled with rhodamine-lissamine dye prior to Faglu fixation. The cell was viewed with filters appropriate for rhodamine fluorescence. $C$, Same CBI-1 as in $B$, which following FaGlu fixation appeared bluish green when viewed with a filter appropriate for catecholamine fluorescence. Calibration bars, $A, 1 \mathrm{~mm} ; B$ and $C, 50 \mu \mathrm{m}$. 


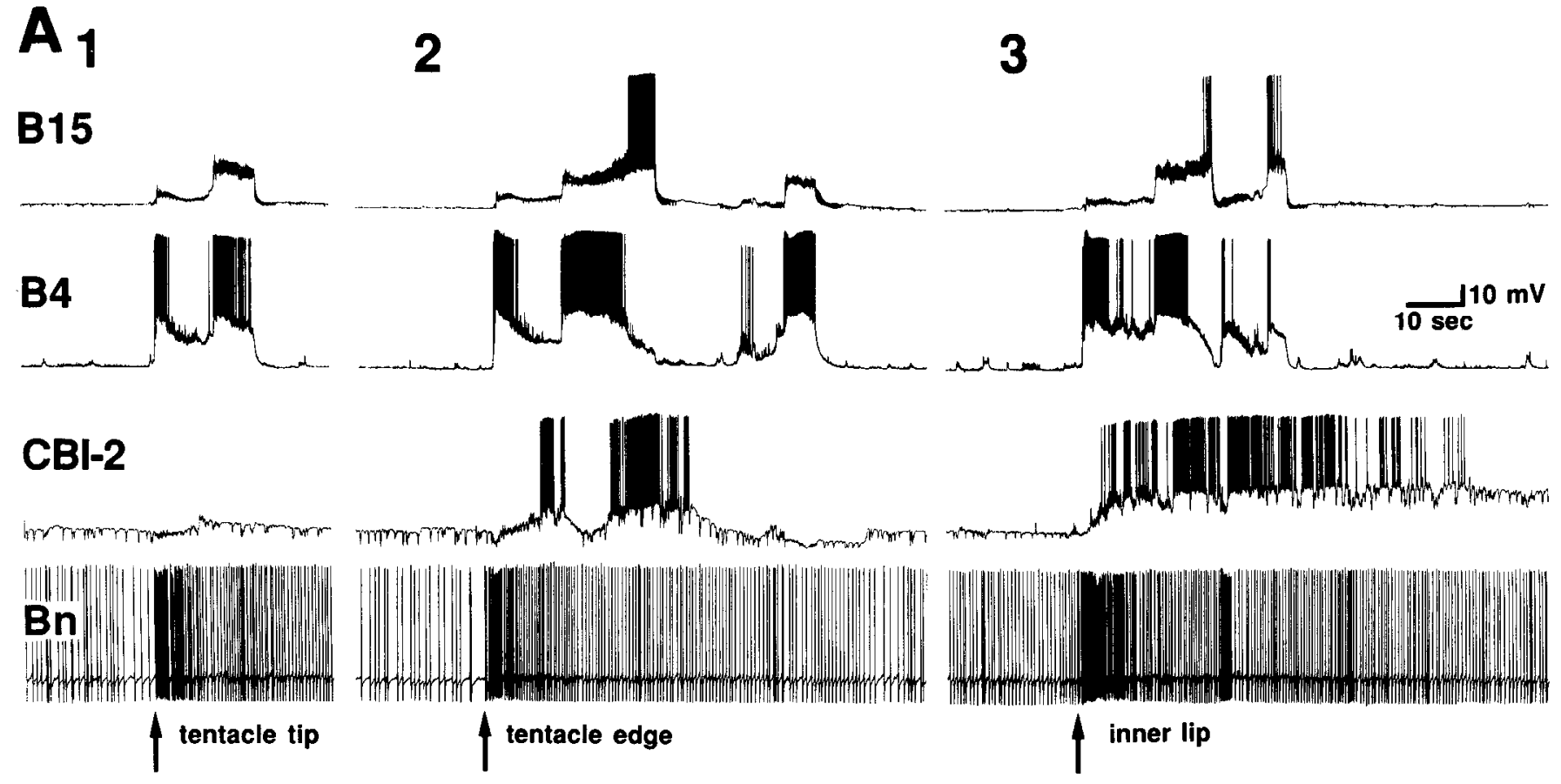

B
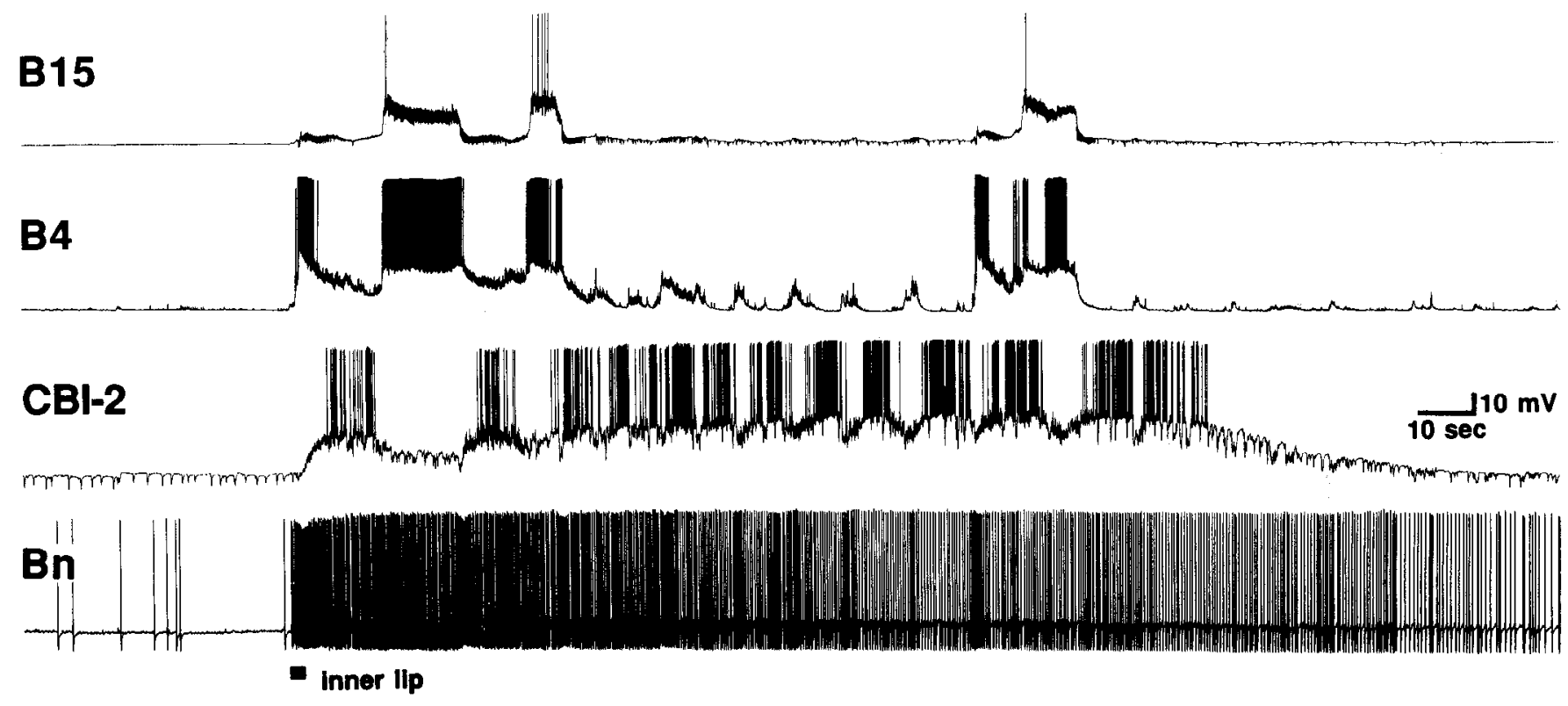

Figure 15. Responses of $C B I-2$ to mechanical and chemical stimuli applied to the tentacles and lips. Control recordings were made of $B 15$, $B 4$, $B n$ activities. The stimuli were a punctate mechanical stimulus (tip of glass rod, $1 \mathrm{~mm}$ in diameter) applied briefly (50 msec) to the tip of the anterior tentacle ( $A I$, at arrow), the same stimulus as in $A I$ applied to the anterior edge of the tentacle $(A 2)$, the same stimulus as in $A I$ applied to the inner lips and perioral zone, which evoked a prolonged depolarization and sustained firing of $C B I-2(A 3)$, and a solution of seaweed extract $(50 \mu 1)$ gently applied over the lips and perioral zone $(B$, short horizontal line at bottom). The seaweed stimulus evoked a sustained depolarization and rhythmic firing of $C B I-2$ lasting several minutes. Rhythmic synaptic input to $B 4$ was also observed, as well as a sustained discharge of the cerebral $B n$ neuron.

four preparations (Fig. 14A). To determine the identity of this cell, we impaled the CBIs with a double-barreled microelectrode, one barrel of which contained rhodamine-lissamine dye. Following identification of the cell by its electrophysiological properties, the dye was iontophoretically ejected into the cell and the tissue was subsequently fixed. When viewed in the fluorescence microscope with appropriate filters, only positively identified CBI-1 neurons $(n=4)$ showed both rhodamine (red;
Fig. 14B) and dopamine (blue-green; Fig. 14C) fluorescence. No other dopamine-positive cells were found in the M-clusters of these preparations.

\section{$C B I-2$}

Studies of CBI-2 indicate that it serves a function quite different from CBI-1. Its properties suggest that it may be a pattern- 


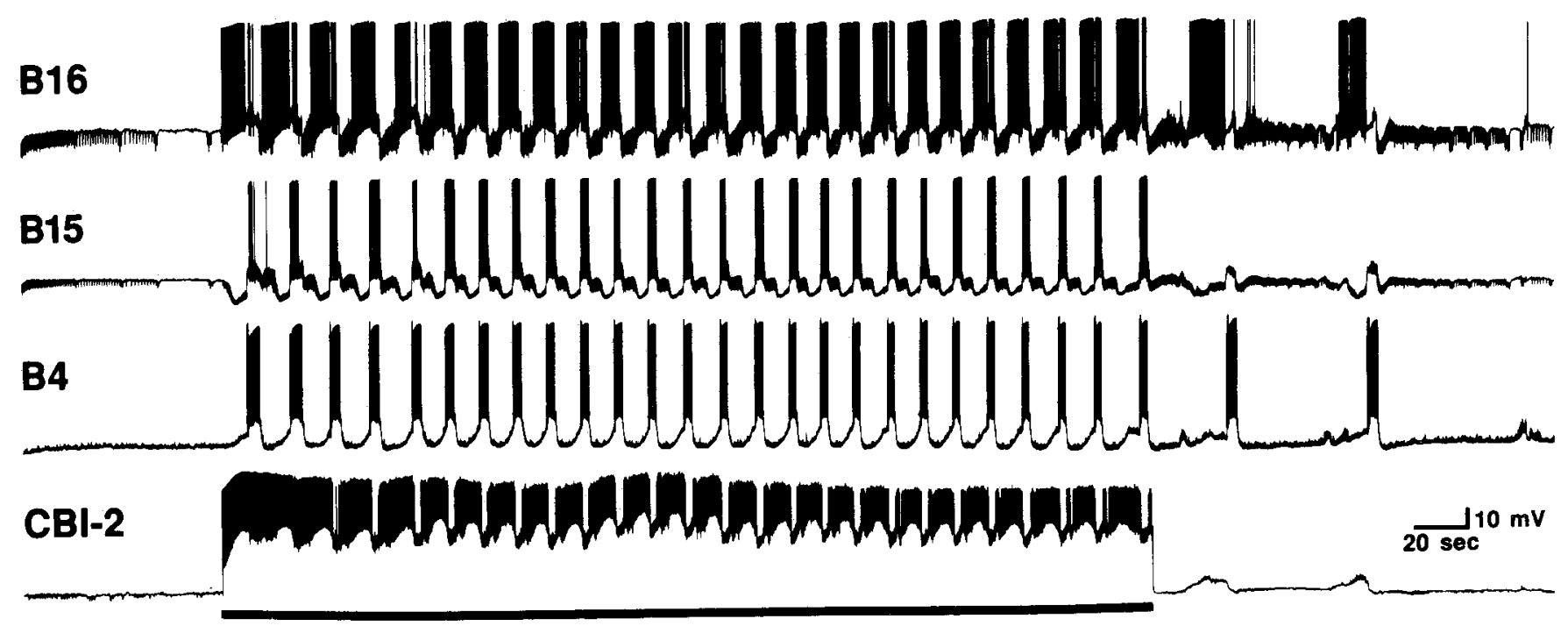

Figure 16. Depolarizing intracellular stimulation of $C B I-2$ with a 350 sec constant-current pulse, sufficient to elicit a phasic train of spikes, evoked a rhythmic BMP that incorporated spiking activity in identified buccal motor neurons $B 15$ and $B 16$, and in interneuron $B 4$.

initiating neuron that may also contribute to the shaping of the motor output.

CBI-2 sensory responses. Tactile or chemical stimuli applied to the lateral tips of the tentacles generally produced inhibition of CBI-2, although these same stimuli provided excitation to buccal cells B4 and B15 and to the Bn neurons of the cerebral B-clusters (Fig. 15Al). The same stimulus applied to the leading edge of the tentacles evoked a compound inhibitory and excitatory response in CBI-2 (Fig. 15A2). The excitatory component appeared to be linked to a cycle of coordinated bursting activity evoked in the buccal cells. The patterns of bursting in neurons B4 and B15 were reminiscent of those evoked by CBI-1, which in this preparation was probably excited by the tactile stimulus. When a tactile stimulus was applied to the inner lips, however, CBI-2 exhibited a prolonged depolarization accompanied by sustained firing that outlasted the coordinated bursting activity, which was also evoked in buccal cells B4 and B15 (Fig. 15A3). The activity of CBI-2 also outlasted that of the cerebral Bn neuron. When a solution of seaweed extract was applied to the inner lip region and the perioral zone, CBI-2 received powerful excitatory inputs that gave rise to tonic depolarization of the cell and sustained rhythmic firing (Fig. 15B). A potent chemical stimulus, such as a piece of seaweed, pressed against the inner lips could cause CBI-2 to fire at a rate $(>10 \mathrm{~Hz})$ equivalent to that which could drive repetitive cycles of a BMP (see section below).

Direct connections of $C B I-2$. We have been unable to identify positively direct sensory inputs to CBI-2 or monosynaptic outputs to most of the neurons that are incorporated in the BMP driven by CBI-2. Although CBI-2 produces slow EPSPs in neurons $\mathrm{B} 4$ and $\mathrm{B} 5$ (Fig. 7B), the EPSPs are blocked by the presence of high concentrations of divalent cations in the bathing medium. We have, however, identificd two buccal neurons that send axons to the cerebral ganglion that appear to be directly connected to CBI-2. One, B19, produces a compound, slow inhibitory-excitatory (I/E) PSP onto CBI-2 that persists in highdivalent-cation ASW (Rosen, Weiss, and Kupfermann, unpublished observations), and another, which is the previously identified buccal cell B17 (Chiel et al., 1988), receives an EPSP from
CBI-2 that persists in high-divalent-cation ASW long after the responses in neurons B4 and B5 are abolished.

Motor program elicited by $C B I-2$. Intracellular stimulation of CBI-2 with depolarizing, constant-current pulses sufficient to elicit spike trains evoked robust, rhythmic patterns of neuronal activity (seen in 58 of 60 preparations) that could be recorded from the same classes of cerebral and buccal neurons activated by CBI-1 (Figs. 16-18). The coordinated patterns of bursting persisted as long as CBI-2 continued to fire above a threshold frequency $(7-13 \mathrm{~Hz})$ and ceased within a cycle or two following termination of the stimulus. Figure 16 shows that constantcurrent, intracellular stimulation applied for approximately 6 min produced a highly rhythmic BMP that persisted for the duration of the firing of CBI-2 and incorporated the phasic activity of buccal motor neurons B4, B15, and B16. BMPs driven by CBI- 2 typically continued for as long as the cell was fired, provided that the firing frequency of CBI- 2 was maintained. In $28(47 \%)$ of 60 neurons tested, CBI-2 firing exhibited accommodation, which resulted in a lowering of the spike rate and a slowing or termination of the BMP (see Fig. 17). The program could be repeatedly elicited regardless of the interstimulus interval. The ability to fire CBI-2 repeatedly at high rates, however, improved after periods of rest.

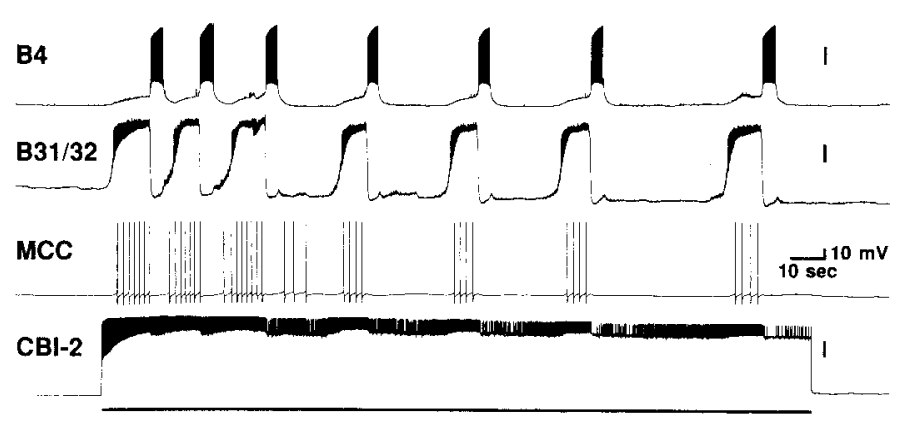

Figure 17. The motor program driven by $C R I-2$ incorporated the rhythmic activity of nonspiking, putative CPG buccal neurons $B 31 / B 32$ and the cerebral neuron $M C C$. Vertical calibration bars, $10 \mathrm{mV}$. 

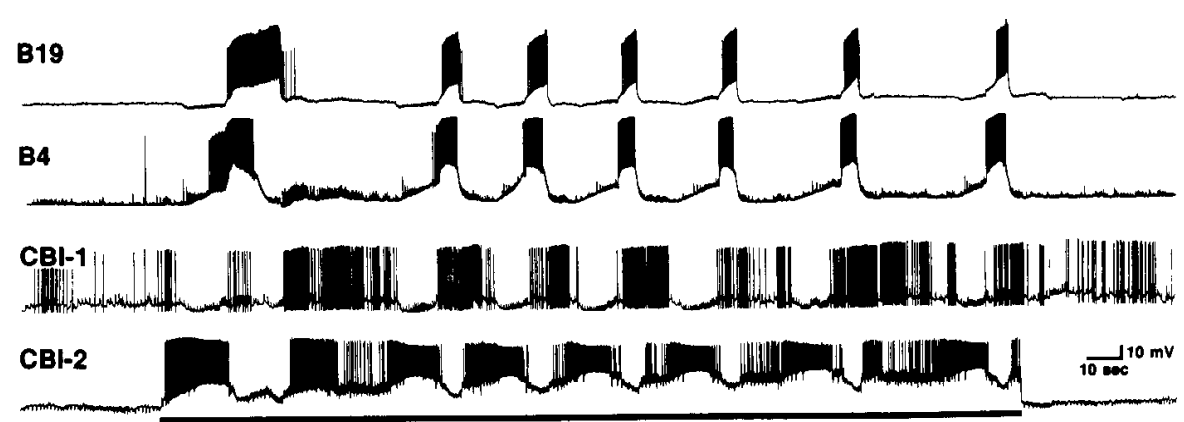

Figure 18. The motor program driven by $C B I-2$ incorporated the phasic activity of $C B I-I, B 4$, and $B C I B I Y$, which provides feedback inhibition and $\mathrm{ex}$ citation to $C B I-2, C B I-I$ was often spontaneously active, but during the $C B I$-2-driven motor program its activity became phase-linked to that of $C B I$ 2 , showing phasic inhibition during accelerated bursts of $C B I-2$ firing.
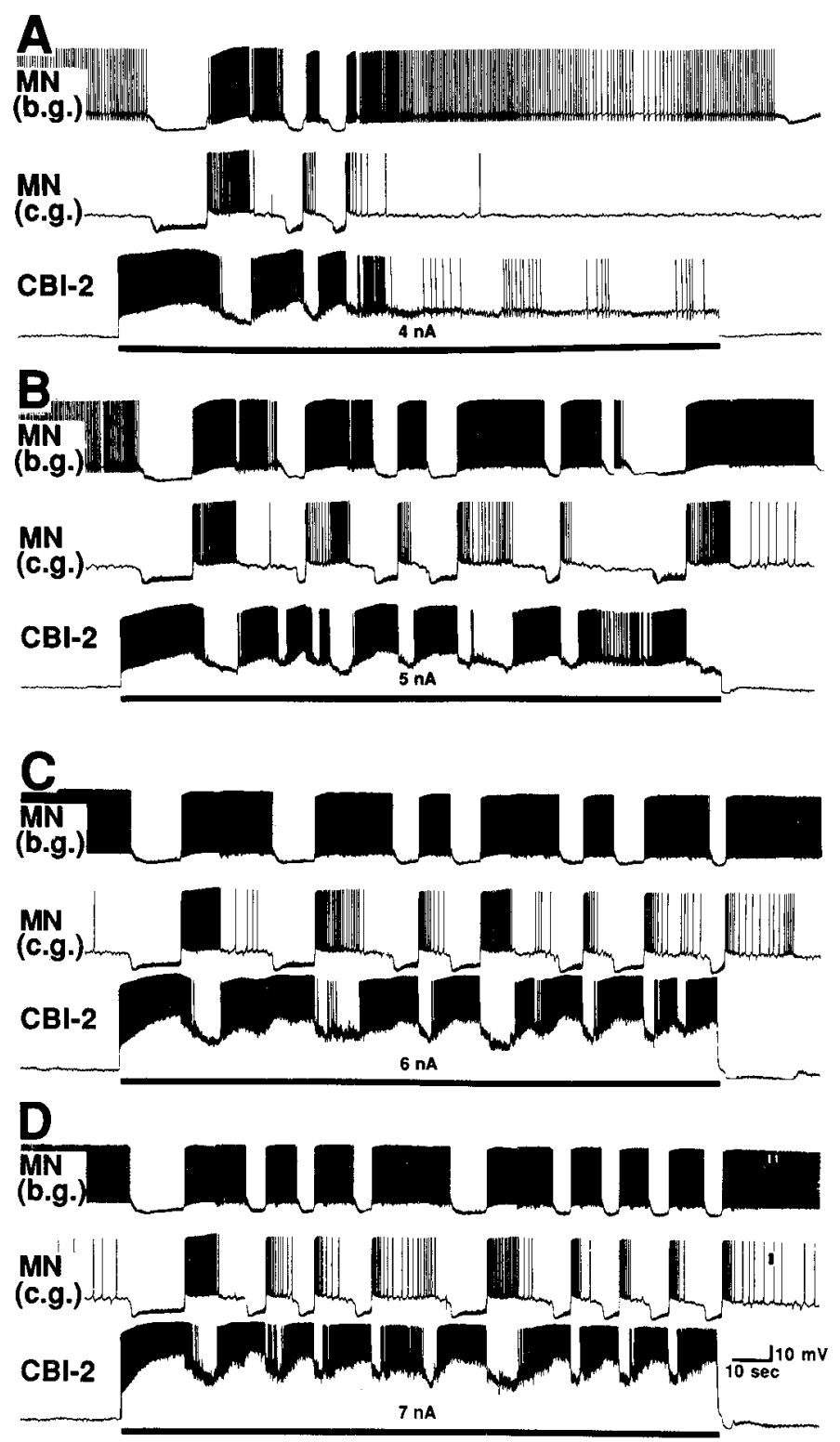

Figure 19. Effects of varying the excitatory drive to $C B I-2$ on its ability to drive a motor program. The motor program was monitored by intracellularly recording the activity of a representative cerebral ganglion (c.g.) and buccal ganglion (b.g.) motor neuron $(M N)$. Systematically varying the intracellular current used to fire CBI-2 tonically indicated a threshold for firing below which no rhythmic activity was observed (not shown). $A$, Threshold firing ( $4 \mathrm{nA}$ current) produced several cycles of the motor program following the onset of stimulation. The program
Since the phase relations of the firing of B15 and B 16 in freemoving animals during biting, swallowing, and rejection are known (Cropper et al., 1990), we examined the phasing of B15 and $\mathrm{B} 16$, as well as that of B4, during the rhythmic BMP driven by C.BI-2. In 10 of 10 preparations, B16 activity preceded that of B15 within each cycle of the program (Fig. 16). The cells then fired together, in phase with the bursting of B4. B15 activity began synchronously with that of B4. B16 continued to fire during the $\mathrm{B} 4$ burst, but at a reduced rate. The relationship of B15 to B16 activity was similar to that determined for biting, but not swallowing or rejection responses, observed in intact, feeding animals.

To determine the effect of CBI-2 on buccal and cerebral neurons that may be involved in generating and modulating the BMP, we recorded from putative pattern-generating neurons, B31/B32 (Susswein and Byrne, 1988), and the serotonergic MCCs (Weiss et al., 1978). Figure 17 shows that the firing of CBI-2 led to the phasic firing of B31/B32, as well as B4 and the ipsilateral MCC. In six of six preparations, the slow depolarization of B31/B32 preceded the B4 burst and was abruptly terminated with the onset of B4 activity. The form of the burst pattern of B31/B32 was indistinguishable from the single cycle of burst activity evoked by CBI-1 (see Fig. 10A). In addition to driving a rhythmic motor program that incorporated putative patterngenerating, neuromodulatory, and motor neurons, we found that the motor program driven by CBI-2 also incorporated other CBIs (see Figs. 25, 28), including CBI-1 and a BCI, B19 (Fig. 18).

In order to determine whether variations of the magnitude of the excitatory drive to CBI-2 might be capable of modifying the character of the motor program it drove, CBI-2 was fired by means of long-duration, constant currents of various magnitudes. At some threshold level of current ( $4 \mathrm{nA}$ for the experiment shown in Fig. 19A), an aborted pattern of rhythmic bursting was recorded in cerebral and buccal motor neurons. A suprathreshold stimulus ( $5 \mathrm{nA}$ ) initiated a rhythmic burst pattern that persisted for the duration of the intracellular stimulus (Fig. 19B). At higher levels of stimulation (6 and $7 \mathrm{nA}$ ), the latency to the onset of the first cycle of bursting decreased and

\footnotetext{
$\leftarrow$

ceased, although CBI-2 remained depolarized. $B$, Stimulation of $5 \mathrm{nA}$ produced a sustained program that showed bursting patterns of variable duration. $C$, Stimulation of $6 \mathrm{nA}$ produced a more regular rhythmic motor program of greater frequency and shorter latency to the onset of the first cycle. $D$, Stimulation of $7 \mathrm{nA}$ produced a still shorter-latency, higher-frequency, and more regular program. The data were similar for an ascending (shown here) or descending series of stimulating currents, not shown.
} 


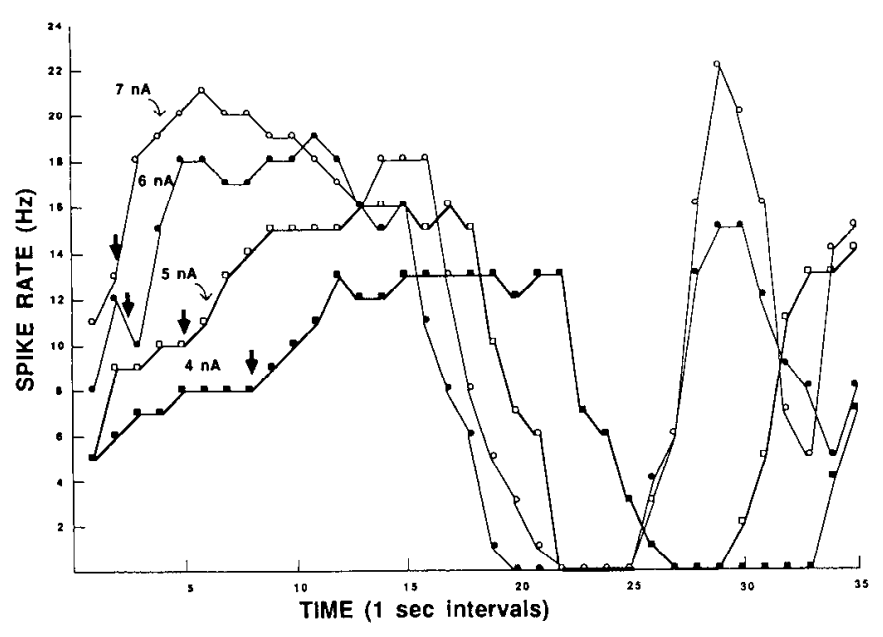

Figure 20. Plot of the frequency of firing of CBI-2 as a function of time ( 1 sec intervals) for the four levels of intracellular stimulus currents shown in Figure 19. Arrows show the onset of the first cycle of the motor program evoked by CBI- 2 activity. The drop in frequency corresponds to the end of a cycle and is due to inhibitory feedback from the buccal ganglion.

the overall frequency of bursting increased (Fig. 19C,D). Higher current levels produced no further changes in burst frequency or regularity. Over a range of currents that produced a marked variation of peak spike frequency (Fig. 20), the rate of the rhythmic program exhibited only a slight increase, although the higher currents elicited programs that were more regular (Fig. 19D).

A plot of the instantaneous spike frequency over the first 10 sec of stimulation for different levels of constant current (Fig. 20) revealed that, with low levels of depolarizing current, spike frequency increased very slowly. In the example given, at $4 \mathrm{nA}$ of current the CBI-2 spike frequency did not reach a peak until 15-20 sec, whereas at $7 \mathrm{nA}$ the peak was reached in 5 or $6 \mathrm{sec}$. This behavior of the cell is reminiscent of other Aplysia neurons that possess an inactivating, voltage-dependent potassium current. This current is not inactivated at the high resting potential of some Aplysia neurons (Carew and Kandel, 1977; Byrne, 1980). The resting potential of CBI-2, however, in these experiments was relatively depolarized (mean, $48 \mathrm{mV} \pm 4.6 \mathrm{SD}$ ), suggesting that the cells may have an inactivating potassium current that is of the $I_{\mathrm{AD}}$ type (Y. Furukawa, E. R. Kandel, and P. Pfaffinger, unpublished observations).

Since CBI-2 fires phasically during the buccal program it elic- its, we examined whether the rate at which CBI-2 bursts occur has any effect on the BMP. By means of repeated depolarizing pulses, CBI-2 was driven in bursts similar to those seen during its firing with constant-current depolarization, and the burst frequency was varied. At low rates of CBI-2 bursting $(2.4 / \mathrm{min})$, the cell was capable of driving a cycle of a BMP with each burst of CBI-2 activity (Fig. 21 A). As the frequency of CBI-2 bursting was increased $(4.8 / \mathrm{min})$, the rate of buccal bursts increased, one for one (Fig. $21 \mathrm{~B}$ ). At a high rate of CBI-2 bursting $(6 / \mathrm{min})$, the cycling of the BMP began to fail to follow the CBI-2 activity (Fig. 21C). This experiment shows that aspects of the phasic information transmitted by CBI- 2 are conveyed to the buccal ganglion, and that the effects of CBI-2 are fast enough so that it can drive the BMP on a cycle-by-cycle basis, rather than simply gating a program. However, as will be shown in a forthcoming report (Rosen, Weiss, and Kupfermann, unpublished observations), phasic activity of CBI-2 is not necessary for a rhythmic BMP to be generated by the firing of the cell.

\section{$C B I-3$}

$C B I-3$ sensory responses. Tactile and chemical stimuli applied to the lips and tentacles of semi-intact preparations evoked robust responses in CBI-3. A brief (100 msec), punctate tactile stimulus (von Frey hair) that was applied to the tip of the tentacle (Fig. 22AI) and that was sufficient to evoke a weak, unilateral, withdrawal response, elicited a train of CBI-3 spikes that was usually associated with a single cycle of a coordinated bursting activity recorded from buccal neurons (e.g., B4, B15). The response often outlasted the burst of spikes that was also recorded from a cerebral Bn neuron. A similar stimulus applied to the anterior edge of the tentacle could also evoke a sustained burst of CBI-3 spikes that outlasted the Bn response, even though a complete cycle of coordinated buccal bursting activity was not elicited (Fig. 22A2). When a tactile stimulus was applied to the lips, a very robust train of CBI-3 responses was triggered. If the stimulus was maintained on the lips, the response persisted for minutes and showed only modest adaptation (Fig. 22A3). The most robust responses of CBI-3 were observed when a small piece of seaweed was gently applied to the inner lips (Fig. 22B). The stimulus evoked a tonic depolarization of CBI- 3 that was accompanied by sustained firing of the cell. The stimulus was also sufficient to elicit a rhythmic BMP for the period of the stimulus application. The response of CBI-3 outlasted both the duration of the stimulus and the activity of the buccal cells.
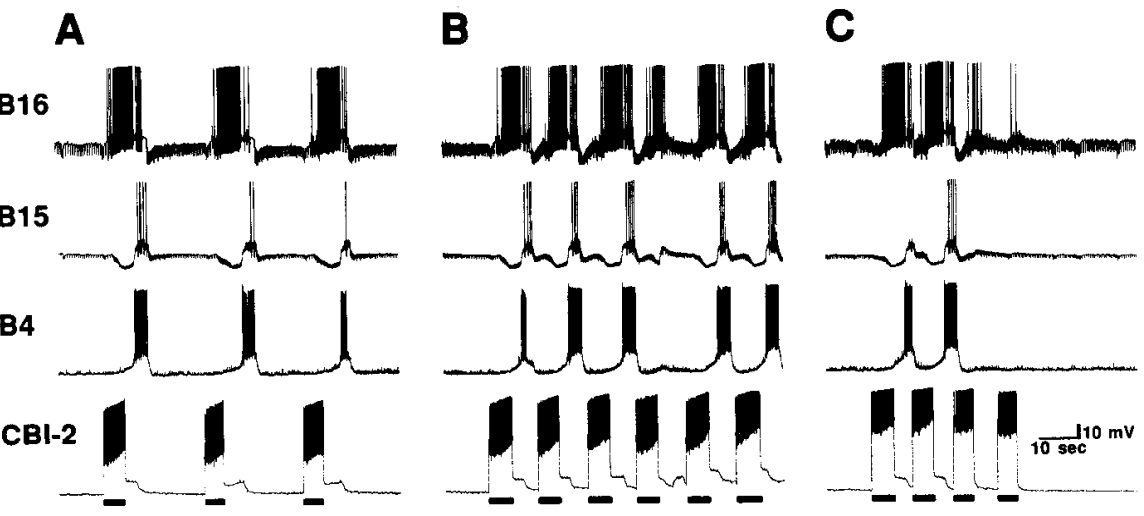

Figure 21. $A$, Repetitive periods of $C B I-2$ stimulation $(2.4 / \mathrm{min})$ produced bursts of spikes that drove single cycles of a BMP (buccal motor neurons $B 4$, $B 15$, and $B 16$ are shown). $B$, When the rate of repetitive stimulation was increased to $4.8 / \mathrm{min}$, single cycles of the BMP continued to follow the $C B I-2$ bursting rate. $C$, At higher rates $(6 / \mathrm{min})$, the BMP failed to follow, one for one, the rate of $C B I-2$ bursting. 


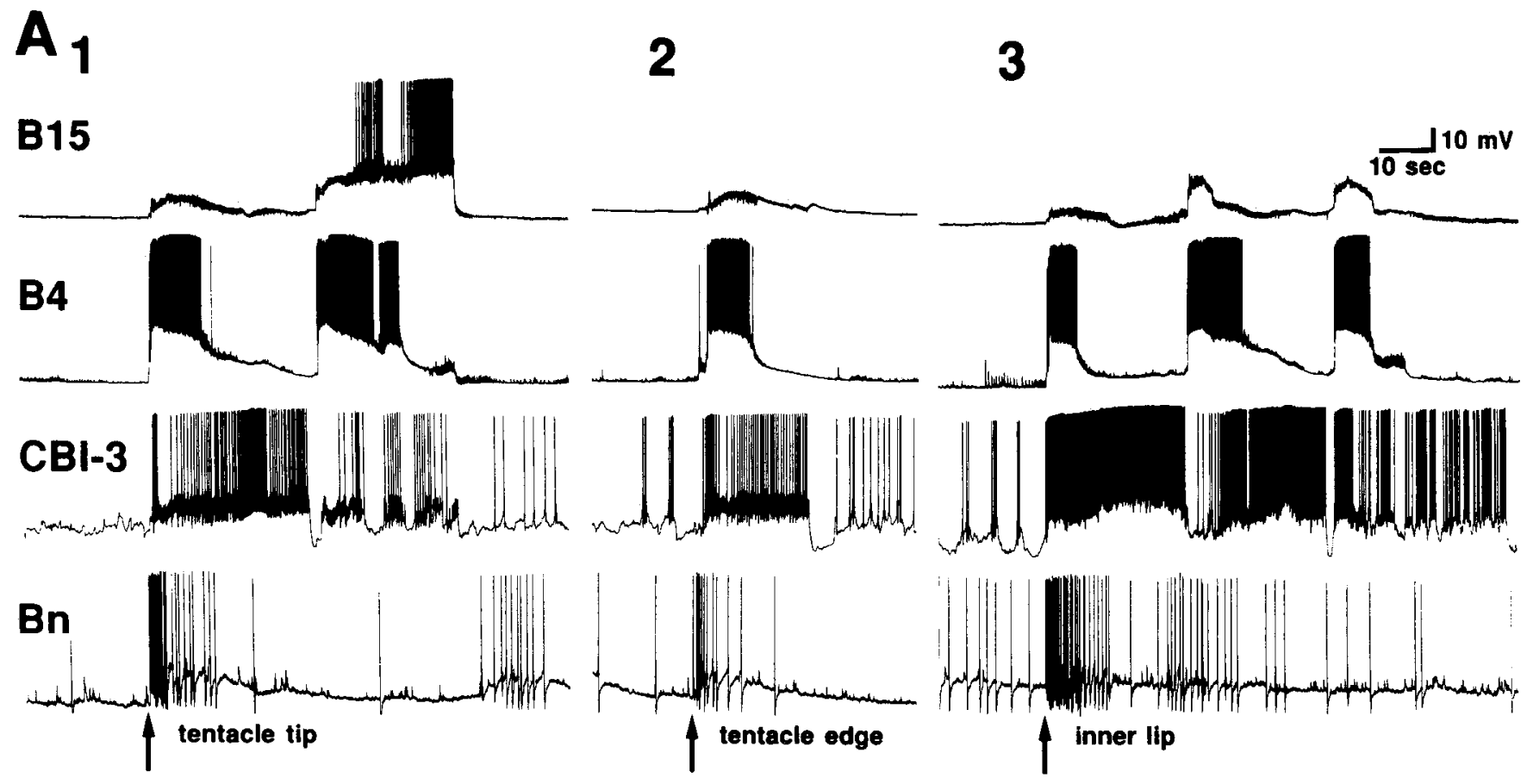

B

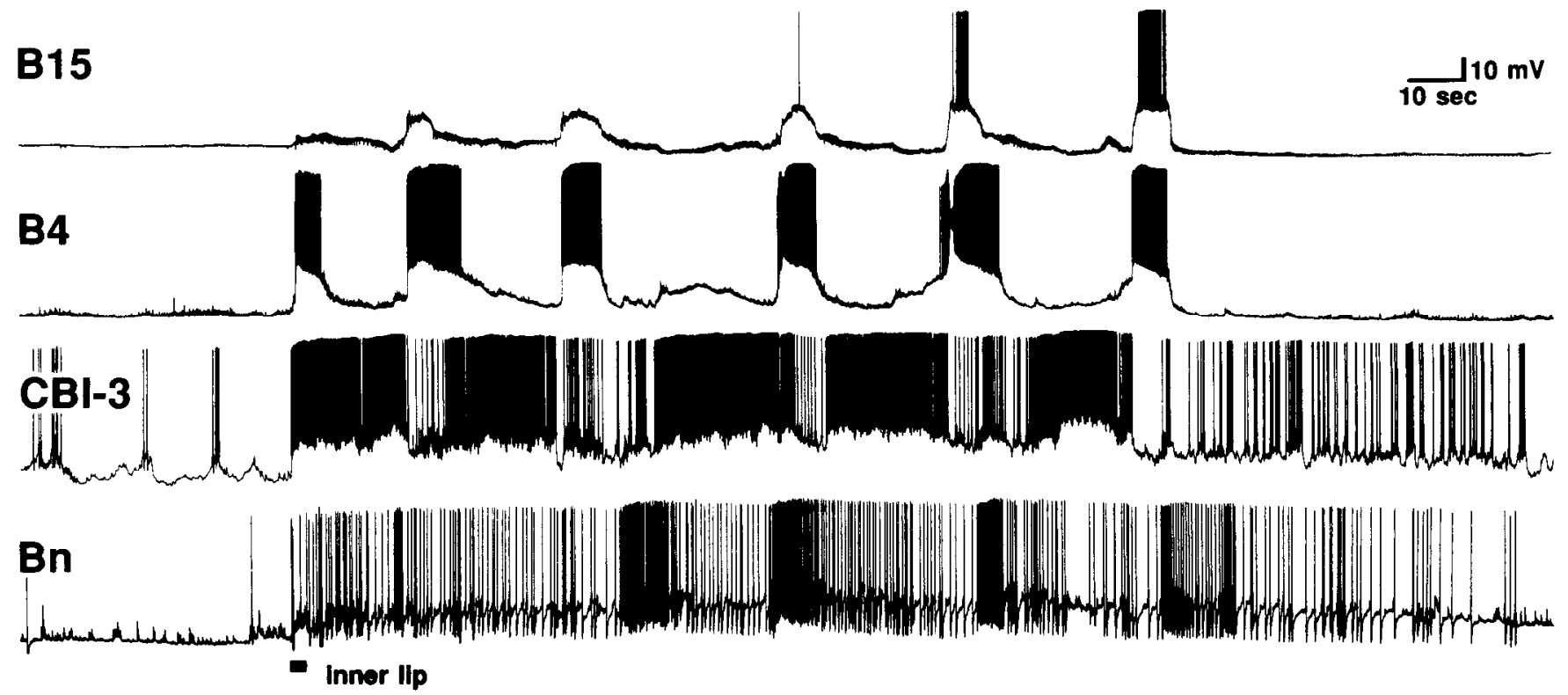

Figure 22. Responses of $C B I-3$ to tactile and chemical stimuli applied to regions of the anterior tentacles and lips. $B 15, B 4$, and a cerebral $B n$ cell are also shown in control recordings. $A 1$, A brief $(100 \mathrm{msec})$ tactile stimulus (von Frey hair) applied to the tip of the ipsilateral tentacle evoked a sustained response in $C B I-3$, and a cycle of coordinated bursting activity in buccal cells. A discharge of a $B n$ cell and a unilateral, tentacular withdrawal response were also observed. $A 2$, A similar stimulus applied to the anterior edge of the tentacle evoked a similar $C B I-3$ response, although the complete cycle of buccal bursting activity was absent and no withdrawal response was observed. $A 3$, A maintained tactile stimulus applied to the ipsilateral inner lip (onset at arrow; offset not shown) evoked a sustained $C B I-3$ response that persisted for the duration of the stimulus. Several cycles of buccal bursting activity were observed. $B$. A moistened piece of seaweed (Laver; $4 \mathrm{~mm}^{2}$ ) applied to the inner lips evoked a prolonged depolarization and sustained firing of $C B I-3$. The stimulus evoked a rhythmic BMP associated with rhythmic lip and tentacle contractions and concomitant bursting activity of the $B n$ neuron.

Synaptic outputs of CBI-3. Like CBI-1, CBI-3 produced PSPs in many neurons comprising the ventral motor neuron cluster of the buccal ganglion. Both EPSPs and IPSPs were produced, depending upon the properties of the follower cell (Figs. 23, 24; Table 2). The firing of single spikes in CBI-3 produced a compound, fast and slow, IPSP in B4/B5 (Figs. 7C, 24B2). The slow
IPSP summated when a train of spikes was elicited in CBI-3. CBI-3 produced slow excitation in both B15 and B16 (Fig. 24BI). The responses persisted unchanged after the ganglia were bathed in ASW containing high concentrations of divalent cations (Fig. $24 B 2$ ), suggesting that the connections are monosynaptic.

$B M P$ elicited by CBI-3. Unlike CBI-1 and CBI-2, sustained 
firing of CBI-3 at relatively high rates $(>10 \mathrm{~Hz})$ did not reliably produce a BMP (Fig. 23). In 3 of 20 experiments, when the preparations were not stimulated for a long period $(10 \mathrm{~min}$ or more), tonic firing of CBI-3 at modest rates $(<10 \mathrm{~Hz})$ produced, after a considerable delay $(>30 \mathrm{sec}$ ), two or more cycles of patterned bursting that resembled the BMP produced by $\mathrm{CBI}-2$ (Fig. 24A). In 17 of 20 experiments CBI-3 had no effect on BMPs. CBI-3 inhibited buccal bursting in 6 of 7 preparations that showed spontaneous burst activity. CBI-3, however, was incorporated into the motor program driven by CBI-2 (see initial activity in Fig. 25). CBI-3 fired rhythmically, and its phasing was appropriate for providing phasic drive to $\mathrm{B} 15$ and $\mathrm{B} 16$, which it monosynaptically excited. When CBI-3 was fired at a high frequency during the motor program driven by CBI-2, it inhibited the program as long as it fired (Fig. 25). When its activity was terminated, the program elicited by CBI-2 resumed its normal rate of cycling.

\section{$C B I-4$}

CBI-4 sensory responses. CBI-4, like CBI-1, CBI-2, and CBI-3, received tactile (Fig. 26A) and chemical sensory input from the lips and tentacles (Fig. 26B). CBI-4 was particularly responsive to seaweed stimuli applied to the lips. Seaweed produced a tonic depolarization of the cell sufficient to elicit a high rate of rhythmic spiking activity. Some of the sensory input to CBI-4 may be direct, since it occurred in the absence of observable evoked secondary activity in the buccal ganglion (Fig. 26A2) and it outlasted the secondary activity evoked by seaweed applied to the lips (Fig. 26B).

Motor program driven by CBI-4. When CBI-4 was fired, similar to CBI-2, it drove a robust, rhythmic program in the buccal ganglion (13 of 15 preparations). Figure 27 shows an example of the CBI-4 program as reflected in two buccal neurons, ARC motor neuron $\mathrm{B} 16$ and multiaction neuron $\mathrm{B} 4$. Unlike the case for CBI-2, the program driven by CBI-4 did not recruit sufficient feedback activity to produce clear phasic firing of itself. Furthermore, the program it recruited had only weak effects on CBI-2 (Fig. 27). Close inspection of the records, however, indicated that when CBI- 4 was fired it evoked a weak excitatory phasic input to itself, but the input was not sufficient to produce obvious phasic modulation of the high firing rate induced by the depolarizing current. By contrast, firing of CBI-2 results in feedback that drives CBI-2 in a phasic manner and also results in the recruitment of phasic activity of CBI-4 (Fig. 28). The recruitment of $\mathrm{CBI}-4$ by $\mathrm{CBI}-2$ may account for the finding that in seven out of eight preparations in which both cells were impaled, the CBI-2-driven buccal program could be made to cycle at a higher rate than the CBI-4-driven program (e.g., compare Figs. 27 and 28). Figure 29 shows that the firing of CBI-4 with intracellular current pulses reinforces the motor program driven by weak stimulation of CBI- 2 .

\section{Discussion}

The present results indicate that the cerebral ganglion of Aplysia contains a small population of CBIs that exert numerous actions on identified buccal cells. This study was designed to provide a basic description of the CBIs. The evidence indicates that, although the CBIs share some features, each has highly distinctive properties. The following sections will consider five aspects of the CBIs: (1) morphology, (2) synaptic connectivity, (3) their effects on patterned neuronal activity of the buccal ganglion, (4)

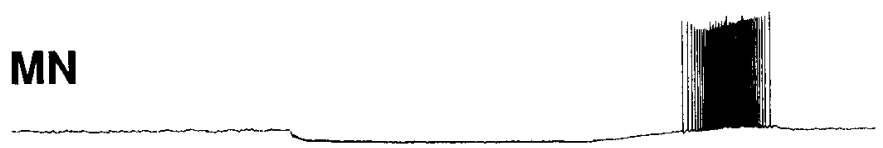

\section{MN}

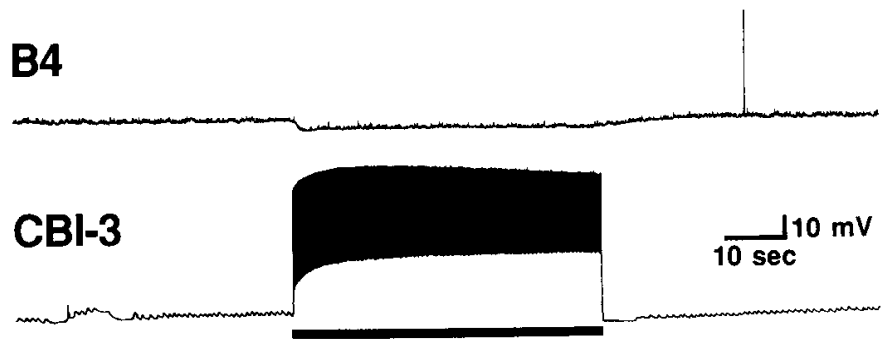

Figure 23. Sustained firing of $C B I-3$ at rates as high as $20 \mathrm{~Hz}$ did not evoke a BMP. Instead, it evoked slow inhibitory potentials in some unidentified buccal motor neurons (e.g., $M N$ in the top trace) and slow excitatory potentials in others (e.g., $M N$ in the second trace), including identified multiaction interneuron $B 4$.

homology with CBIs in other molluscan species, and (5) possible functional roles.

\section{Morphology}

Our data indicate that the cerebral ganglion has a relatively small number of neurons that project axons to the buccal ganglion. Among these are the previously identified MCCs and the ICBM mechanosensory neurons. Each of the MCCs sends one of its two main axons into the ipsilateral C-B connective (Weiss et al., 1978). The main axon then branches and exits buccal nerves. The MCCs are giant, serotonergic cells that have homologs in many species of gastropod and pulmonate mollusks and function to modulate the speed and strength of biting responses (Weiss and Kupfermann, 1976; Gelperin, 1981; Pentreath et al., 1982; Benjamin, 1983; Tuersley and McCrohan, 1988; Rosen et al., 1989c). The ICBMs are mechanosensory cells that have axonal branches in cerebral and buccal nerves that innervate the perioral zone and buccal mass (Rosen et al., 1982, 1989a). The ICBMs are found in two posterior clusters within the cerebral ganglion. A similar clustering of small cells that have cerebral-to-buccal axons (opisthocerebral neurons) has been described in Pleurobranchaea (Gillette et al., 1982). The ICBMs were previously found to make synaptic connections with cells in the buccal ganglion, and a single ICBM action potential could trigger a coordinated burst of buccal output (Rosen et al., 1982). The efficacy of ICBM inputs may be explained in part by the fact that they have direct monosynaptic effects, as well as a polysynaptic action mediated by their excitatory connections to CBI-1 (Fig. 30). Local circuits capable of feedforward summation or feedforward substitution may be a common feature of invertebrate ganglia (Kandel and Wachtel, 1968; Hall and Russell, 1991).

The cerebral ganglion of Aplysia also contains a population of CBIs that, in contrast to the MCCs and ICBMs, do not have axonal branches in peripheral buccal or cerebral nerves. Each hemi-ganglion contains at least four CBIs, each of which has a distinctive morphology. Dye fills have been routinely used in 

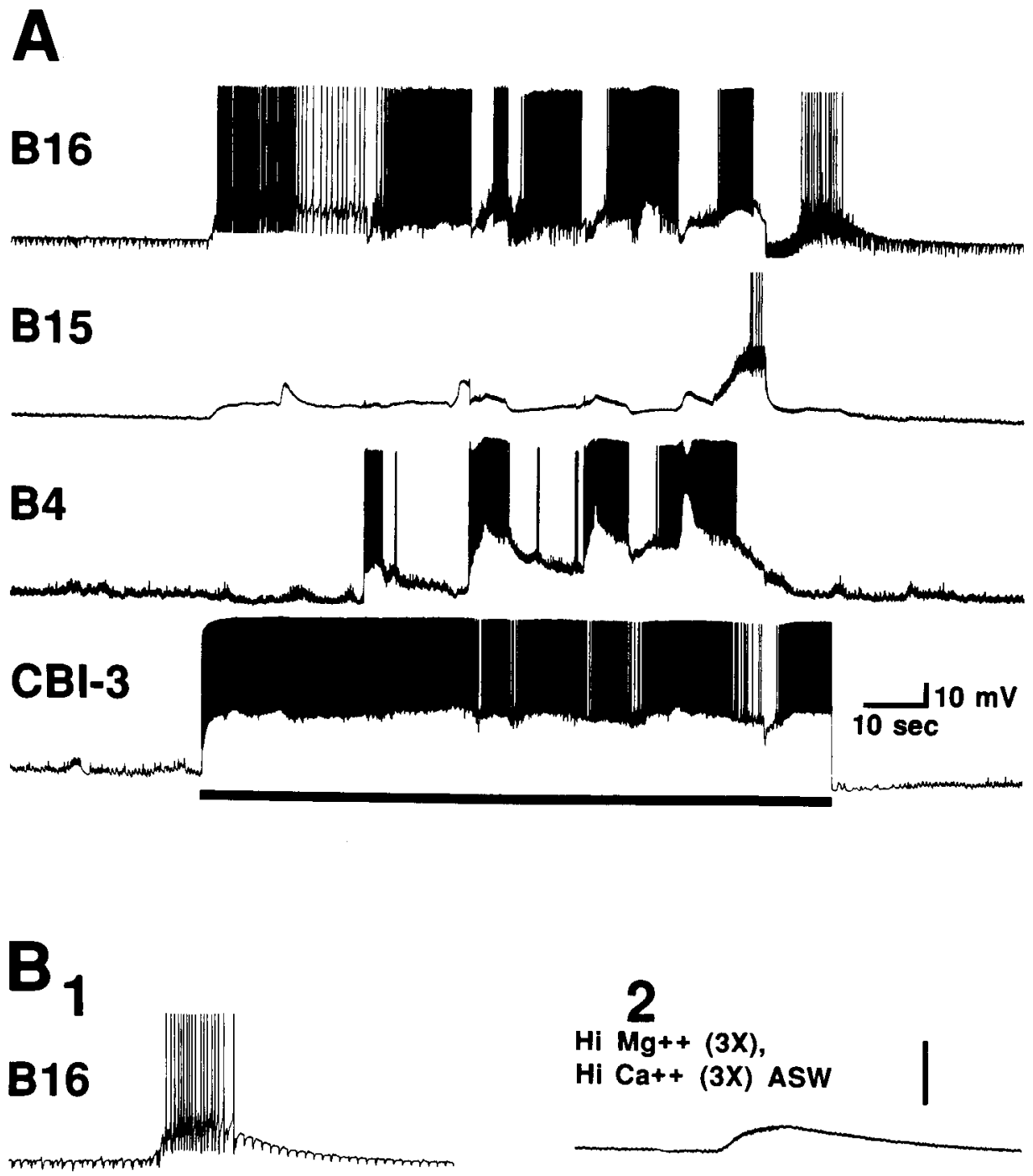

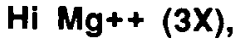

$\mathrm{Hi} \mathrm{Ca++}(3 X)$ ASW

\section{B15}

Figure 24. $A$, Tonic firing of $C B I-3$ at relatively modest average rates (i.e., 7.5 $\mathrm{Hz}$ ) occasionally recruited coordinated bursting activity of buccal motor neurons $(B 4, B 15, B 16)$ after a substantial delay $(>30 \mathrm{sec}) . B 1$, In normal ASW, tonic firing of $C B I-3$ always produced slow excitation in motor neurons $B 15$ and $B 16$, and slow inhibition in neuron $B 4 . B 2$, The slow synaptic events evoked in neurons $B 4, B 15$, and $B 16$ may be the result of direct connections of $C B I-3$ to these cells since the responses persisted unchanged when the cerebral and buccal ganglia were bathed in ASW solutions of high divalent cations $(3 \times$ normal $\mathrm{Mg}^{2+} 3 \times$ normal $\mathrm{Ca}^{2+}$ ).

\section{B4}

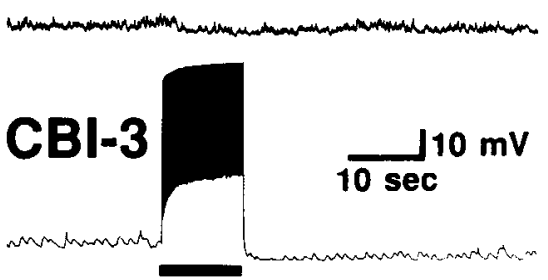

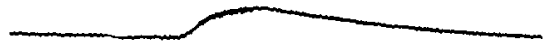

|
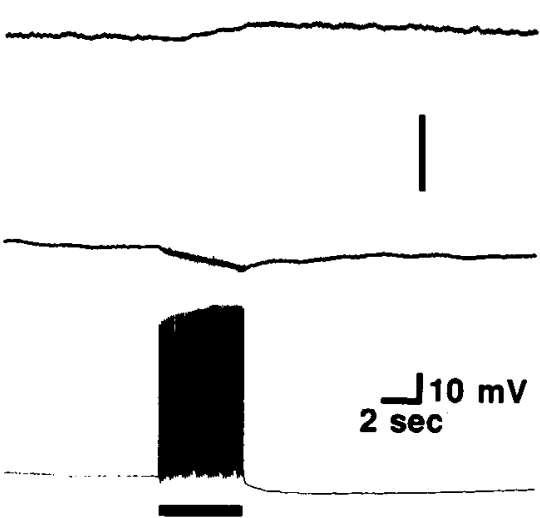

studies of small arthropod neurons, but in our initial studies we found that cobalt or Lucifer yellow often did not fill the distant and fine processes of Aplysia neurons, many of which have a very large volume. 5(6)-carboxyfluorescein dye plus probenecid was found to provide a means for quickly ascertaining the morphology of a cell. The dye readily revealed fine dendritic pro- cesses and larger axonal processes that exited the ganglion. The CBI axons could be followed all the way to the buccal ganglion. The method therefore provided strong indication of whether a cell was a local interneuron (no peripheral axon), an interganglionic interneuron (axon exiting a connective and ramifying in another ganglion), or a sensory or motor cell (axon exiting a 


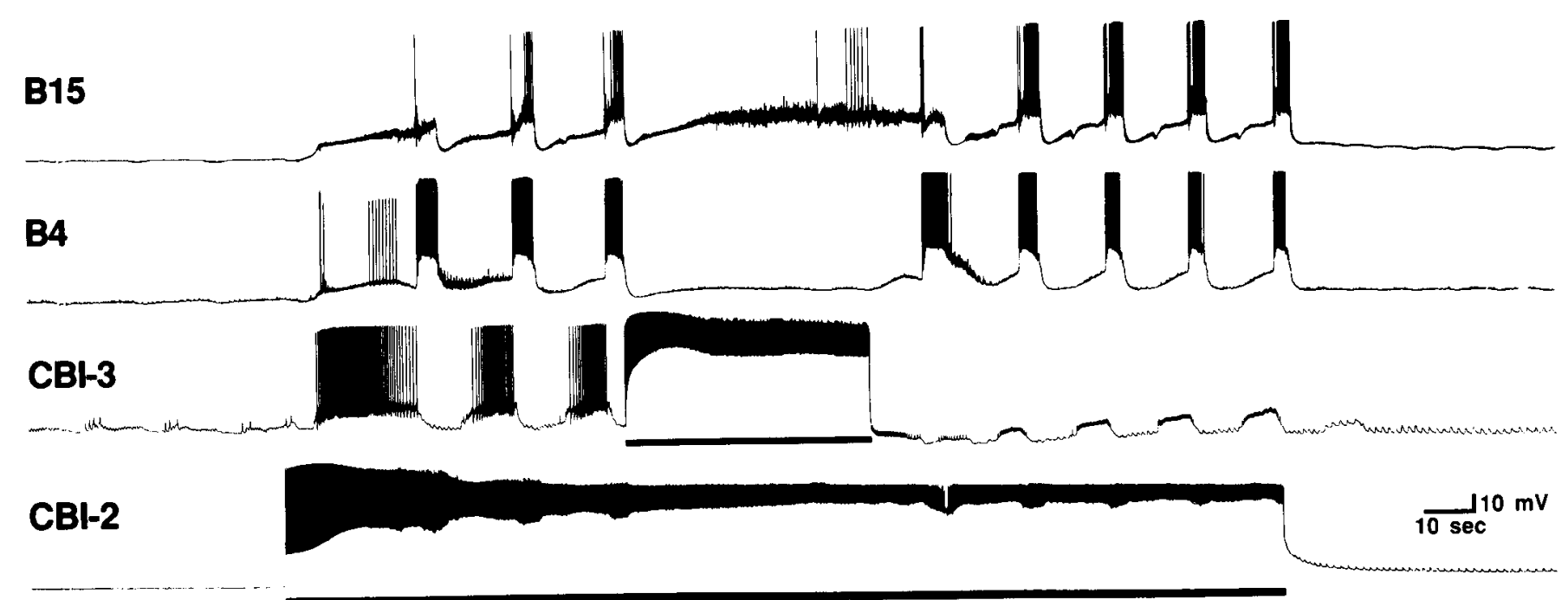

Figure 25. The BMP driven by $C B I-2$, and monitored in motor neurons $B 4$ and $B 15$, evoked phasic activity of $C B I-3$. $C B I-3$ was active during the phase of accelerated firing of $C B I-2$ when $B 4$ and $B 15$ were silent. Tonic firing of $C B I-3$ (horizontal line, $C B I-3$ trace) phase-delayed the BMP driven by $C B I-2$ but did not produce modifications of the program that outlasted the period of $C B I-3$ stimulation. Following stimulation, $C B I-3$ showed an afterhyperpolarization and a blockage of its spiking activity.

peripheral nerve). The dye also revealed details of neuropilar processes that aid in identifying cells as unique individuals. Past studies have not always clearly defined whether particular command-like neurons are unique individuals or are members of a class of indistinguishable neurons. This has contributed to the difficulty of understanding the role of individual command-like neurons in behavior.

With the exception of CBI-1, the morphological differences between the cells are not as distinct as the differences of their physiological actions. CBI-1 has two main axons that project bilaterally to the buccal ganglion. By contrast, CBI-2-4 are monopolar cells that project a single axon in the ipsilateral C-B connective. Nevertheless, the different CBIs have distinctive patterns of dendritic and axonal processes in both the cerebral and buccal ganglia (for details, see Figs. 3, 4), and their relative positions in the ganglion can also be used to distinguish the cells. Although we have reliably identified only $11-13$ of the approximately 20 cells in each cerebral hemi-ganglion that project axons to the buccal ganglion (i.e., 4 CBIs, $1 \mathrm{MCC}$, and 6-8 ICBMs), preliminary data indicate that at least two of the remaining unidentified cells have distinctive properties and can affect buccal neurons implicated in BMPs.

\section{Synaptic connectivity}

We have never seen evidence of any direct connections between the four CBIs themselves. The CBIs, however, receive characteristic patterns of spontaneous synaptic inputs, as well as cyclic synaptic inputs, during BMPs. In addition, CBIs receive distinctive inputs in response to sensory stimulation. For example, CBI- 1 is very effectively excited by mechanosensory inputs from the skin and buccial mass, including muscle associated with the radula, whereas CBI-2, CBI-3, and CBI-4 receive strong excitatory input when the perioral zone is stimulated with seaweed. CBI-2 is notably inhibited by chemical and tactile stimuli applied to the outer lips and tentacles. The inhibition evoked by food stimuli lateral to the perioral zone might serve to sharpen the perioral zone receptive field. The probability of a food stim- ulus evoking a biting response rapidly declines as a function of the distance of the stimulus from the perioral zone (Teyke et al,, 1990). Thus, our findings suggest that CBI-2 may have a special role in eliciting biting responses. This suggestion is also supported by the finding that the BMP driven by CBI-2 incorporates phasic activity of $B 15$ and $B 16$ in a pattern reminiscent of the B15 and B16 pattern observed during biting, but not swallowing or rejection observed in intact, feeding animals (Cropper et al., 1990).

The synaptic output connections of CBI-1-4 were studied, and the data show that the cells have distinctive actions. The CBIs, with the exception of CBI-4, make various types of connections to buccal multiaction interneurons $\mathrm{B} 4 / \mathrm{B} 5$, and these cells provided a convenient assay to aid in distinguishing the CBIs. The CBIs also have actions on gut regulator neurons (B1, B2), ARC motor neurons (B15, B16), BCIs (e.g., B19), and putative $C P G$ neurons (B31, B32). A summary of the monosynaptic and polysynaptic actions is provided in Table 2 . As in other gastropods, command-like neurons that can effectively drive a CPG also have direct access to motor neurons (Gillette et al., 1982; Delaney and Gelperin, 1990b).

\section{Effects on BMPs}

Each of the four CBIs produces markedly different effects on BMPs. Tonically firing CBI- 1 in a rested preparation, regardless of duration, generally produced only a single cycle of coordinated buccal motor activity that involved identified buccal motor neurons (B15, B16), multiaction interneurons (B4/B5), pattern-generating neurons (B31, B32), neuromodulatory cells (MCCs), and pattern-initiating neurons (CBI-2s). The effect differed markedly from that produced by firing CBI-2 or CBI-4. Activation of these cells produced a robust, rhythmic BMP that continued to cycle as long as the cells fired at a rate above 10 $\mathrm{Hz}$. The program driven by CBI-2 incorporated many of the same buccal neurons that were active in the CBI-1-evoked program, as well as cerebral cells, including other CBIs (e.g., CBI-1 and CBI-3), and cerebral lip motor neurons ( $\mathrm{C} 11$ and $\mathrm{C} 12$ ). 

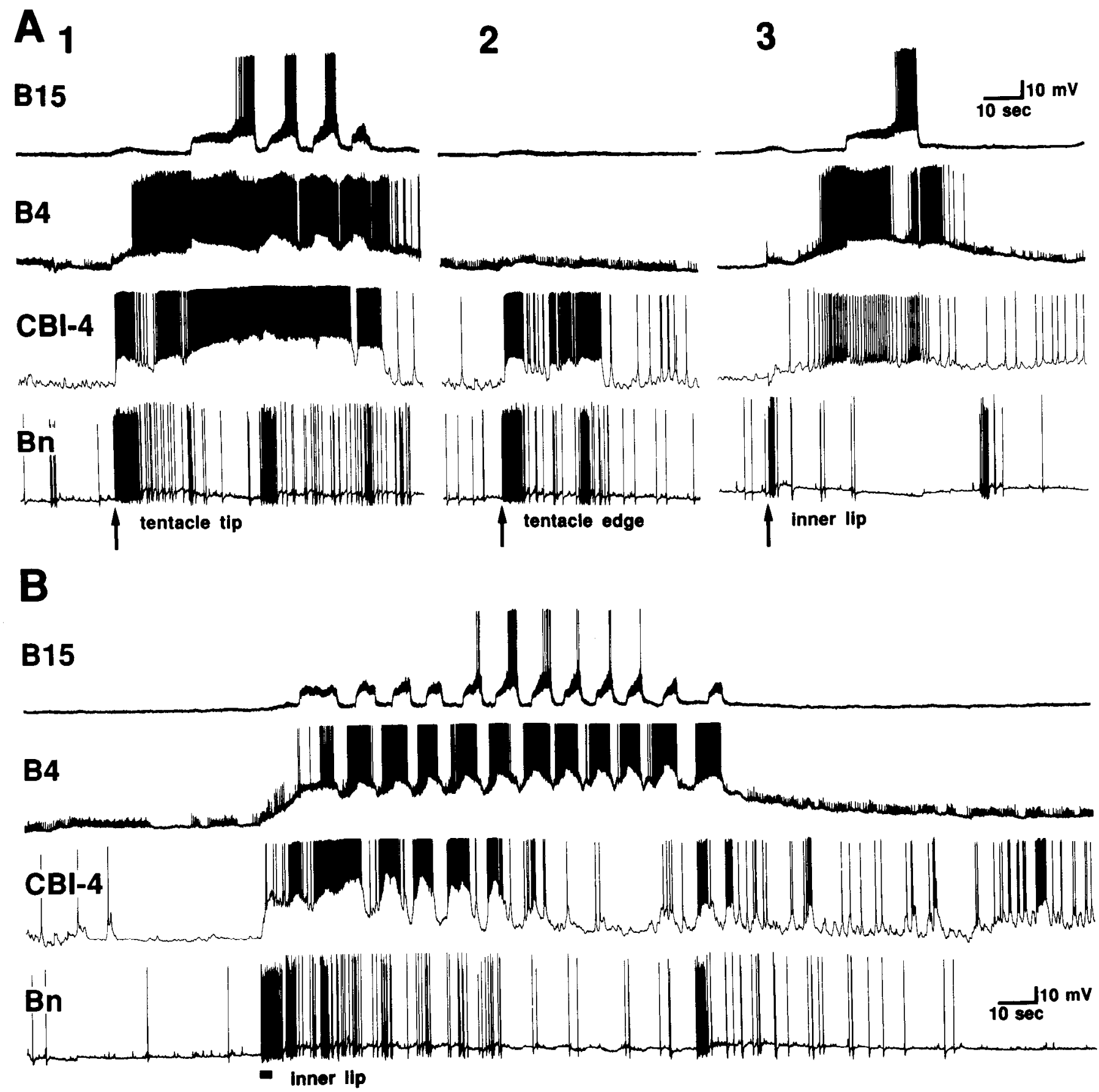

Figure 26. Responses of $C B I-4$ to tactile and chemical stimuli applied to the anterior tentacles and lips of the semi-intact preparation. Control recordings from a cerebral $B n$ neuron and identified buccal motor neurons $B 4$ and $B 15$ are also shown. $A 1$, A brief (100 msec) tactile stimulus (von Frey hair) applied (at arrow) to the tip of the ipsilateral tentacle evoked a sustained response in $C B I-4 . A 2$, A similar stimulus applied to the anterior edge of the tentacle evoked a similar, but less vigorous, $C B I-4$ response. The sustained $C B I-4$ response occurred even though the stimulus did not evoke any obvious buccal activity. $A 3$, A punctate tactile stimulus applied to the ipsilateral inner lip evoked a compound E/I PSP in neuron $C B I-4$, followed by a slow depolarization and a train of spikes. $B$, A moistened piece of seaweed (Laver; $4 \mathrm{~mm}^{2}$ ) applied to the inner lips (at short horizontal line, bottom trace) evoked a prolonged depolarization and sustained rhythmic firing of CBI-4. The firing was accompanied by a rhythmic BMP that ceased when the seaweed was removed from the lips.

Tcrmination of CBI- 2 firing resulted in cessation of the program within a cycle or two. The degree of stereotypy of the BMP, as well as the cycling frequency, was found to be a function of the firing rate of CBI-2. CBI-4 has been less extensively studied, but like CBI-2, fring of this cell evokes a continuous, rhythmic BMP. The cycle rate for programs elicited by $\mathrm{CBI}-4$ was lower than that for CBI-2. This may be accounted for by the fact that stimulation of CBI- 4 does not recruit phasic activity of $\mathrm{CBI}-2$, whereas CBI-2 activity recruits phasic activity of CBI-4, and the cells can be shown to act cooperatively, so that activation of both cells results in a more robust program than if either was activated alone (Fig. 29). CBI-3 failed to evoke a recognizable BMP, but inhibited the motor program evoked by CBI-2, resulting in a phase delay of the program. CBI-3 may be an in- 


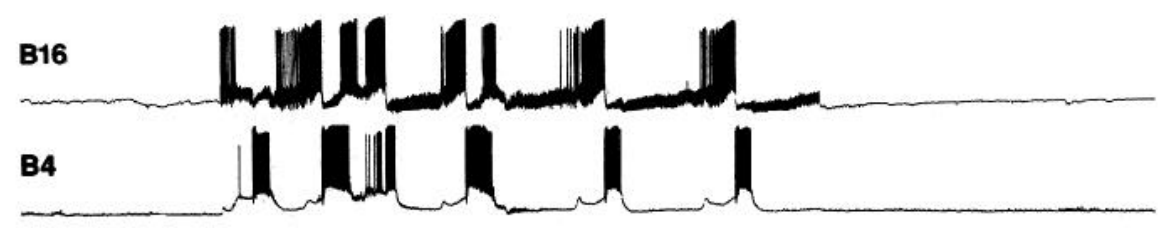

\section{CBI-2}

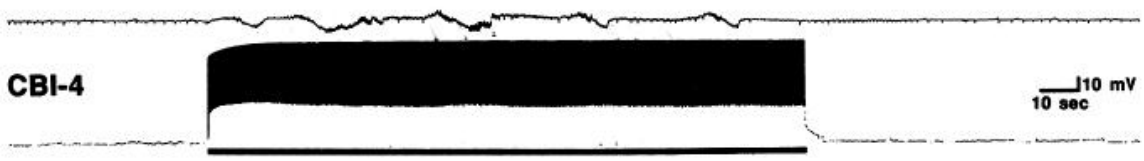

Figure 27. Tonic firing of $C B I-4$ produces a motor program that incorporates buccal motor neurons $B 4$ and $B 16$. The program also produced rhythmic synaptic inputs to $C B I-2$.

hibitory interneuron that is part of the feeding CPG. Neurons located in various ganglia that inhibit buccal programs have been described in several gastropod species (London and Gillette, 1984; Elliott and Benjamin, 1989; Delaney and Gelperin, 1990b; Murphy, 1990).

It is significant that, as in other species (Gillette et al., 1978; Cohan and Mpitsos, 1983a,b; McCrohan and Kyriakides, 1989; Delaney and Gelperin, 1990b), several of the command-like neurons of Aplysia elicit programs that in turn provide feedback to themselves, as well as to the MCCs, which can potentiate BMPs. The command-like neurons and the MCC may provide a source of positive feedback in the control of the buccal mass, in addition to that due to the activity of the histaminergic neuron C2 (see Chiel et al., 1986, 1988; Weiss et al., 1986a-c).

\section{The CBIs may be homologous to neurons in other molluscan} species

A variety of cerebral neurons that send axons to the buccal ganglion have now been described in a number of mollusks (e.g., Pleurobranchaea, Limax, Lymnaea, Aplysia). It is very likely that at least some of these neurons are homologous to the currently described cells in Aplysia, but to ascertain reliable homology, criteria other than morphology and synaptic connectivity must be established, particularly the types of transmitters released from the cells and the responses of the cells to different transmitters. In one case (CBI-1), we have tentatively identified a neurotransmitter (dopamine) contained in the cell, but the transmitters of other CBIs are not known (see, however, Wieland et al., 1987; Rathouz and Kirk, 1988). In the case of CBI-2, we have found that it is strongly driven by exogenous application of ACh (Rosen, Teyke, Miller, Weiss, and Kupfermann, unpublished observations), which is consistent with the actions of ACh on the probable homologs of CBI-2 in Pleurobranchaea and Limax (Morielli et al., 1986; King et al., 1987).
Cells that may be homologous to CBI-2 include the phasic paracerebral $\left(\mathrm{PC}_{\mathrm{P}}\right)$ and polysynaptic exciter (PSE) cells of Pleurobranchaea (Gillette et al., 1982; Kovac et al., 1982, 1983), the CVla cells of Lymnaea (McCrohan and Kyriakides, 1989), and the $\mathrm{CB}_{1}$ cells of Limax (Delaney and Gelperin, 1990a-c). The $\mathrm{PC}_{\mathrm{T}}$ (tonic paracerebral cells) of Pleurobranchaea (Kovac et al., 1982, 1983) may be homologous to CBI-1. The $\mathrm{CB}_{3}$ cells of Limax may be similar to CBI-3, since both cells phase-delay BMPs and both excite or inhibit various types of follower cells (Delaney and Gelperin, 1990b). Finally, CBI-4 may be homologous to CV1b (McCrohan and Kyriakides, 1989) of Lymnaea and $\mathrm{CB}_{4}$ of Limax (Delaney and Gelperin, 1990b). In the early descriptions of the paracerebral neurons (PCNs) in Pleurobranchaea, a distinction was drawn between phasic and tonic types (Gillette et al., 1982; Kovac et al., 1982, 1983). When intracellularly stimulated with a depolarizing current of long duration, tonic cells fired at a constant rate, whereas phasic cells showed periodic bursts of activity due to powerful inhibitory feedback. The phasic type of cerebral-to-buccal cells thus defined include the $\mathrm{PC}_{\mathrm{P}} \mathrm{s}$ and PSEs of Pleurobranchaea (Gillette et al., 1982; Kovac et al., 1983), the $\mathrm{CV1}_{\mathrm{a}}$ cell of Lymnaea (McCrohan and Kyriakides, 1989), the CB1 cell of Limax (Delaney and Gelperin, 1990b), and CBI-2 of Aplysia. These cells have received a good deal of attention because they effectively drive rhythmic motor programs. The tonic types have received less attention because until recently the neurons that were examined were not particularly effective in driving rhythmic motor outputs (e.g., $\mathrm{PC}_{\mathrm{T}}$ of Pleurobranchaea, $\mathrm{CB}_{\mathrm{ST}}$ of Limax, and CBI-1 of Aplysia). However, recent findings of McCrohan and Kyriakides (1989), and our observations of CBI-4, indicate that some tonic cell types can be very effective in driving BMPs. This suggests that tonic-type cells may be divided into at least two types: (1) cells like CV1 $1_{b}$ of Lymnaea and CBI-4 of Aplysia that have clear command-like actions, and (2) cells like CBI-1

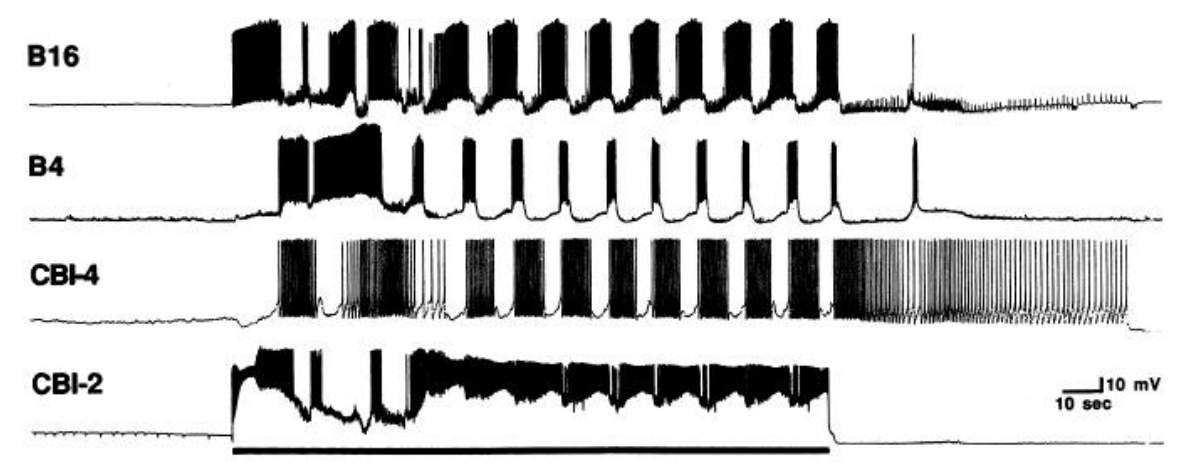

Figure 28. Tonic firing of $C B I-2$ produces a motor program that is associated with phasic activity of $C B I-4$. The $C B I-4$ activity outlasted that of neurons $B 4$ and $B 16$. 
Figure 29. Tonic firing of $C B I-4$ reinforces the program driven by the firing of $C B I-2$. Maintained depolarization of CBI-2 (horizontal line, bottom trace) produced a modest rate of firing that elicited a weak BMP that incorporated the phasic activation of $C B I-4$, $B 4$, and B16. During two intermittent periods of $C B I-4$ stimulation (horizontal lines, $C B I-4$ trace), the cycling rate of the program was increased, the bursting of $B 4$ was intensified, and the cyclic feedback inhibition to $C B I-2$ was accentuated.

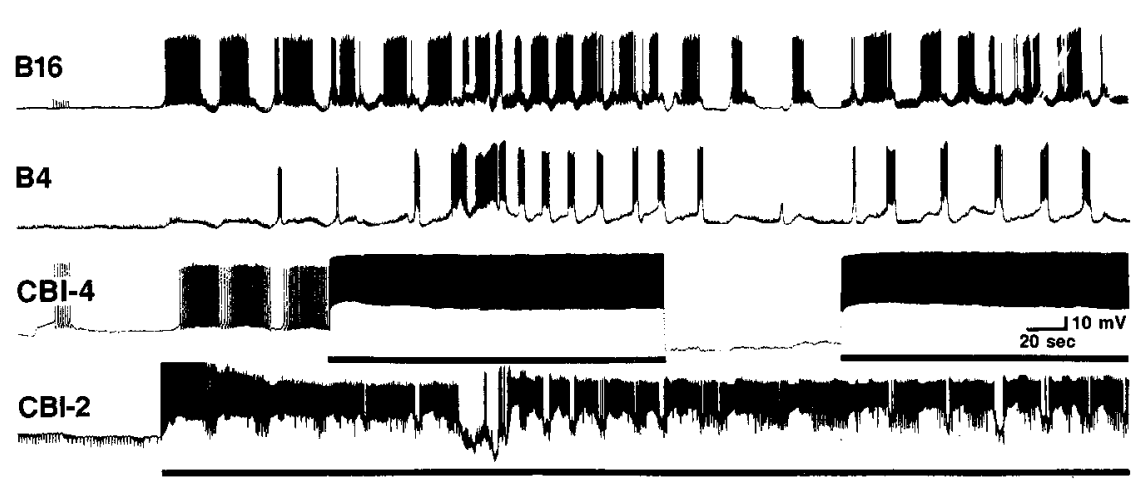

of Aplysia and PCt of Pleurobranchaea that may be modulator neurons that have sufficient access to a CPG to elicit fragments of coordinated output. It is noteworthy that a cell such as CBI-4 appears to be largely tonic when it is depolarized and drives a BMP, but the same cell exhibits a phasic firing pattern when it

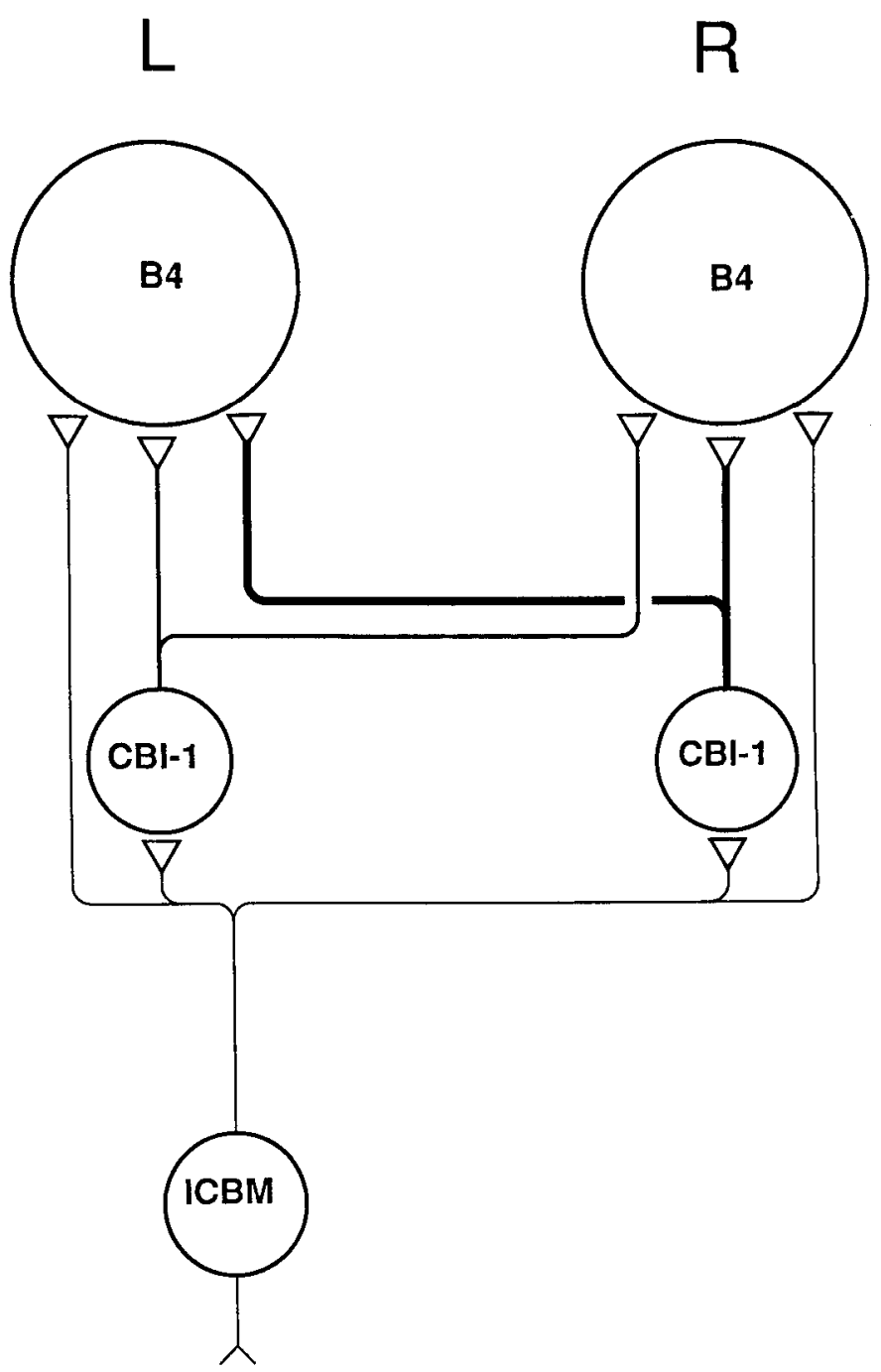

Figure 30. Diagram illustrating how a single $I C B M$ neuron can produce a divergent aggregate of mechanosensory inputs to buccal neurons [e.g., left $(L)$ and right $(R) B 4$ cells] by virtue of its bilateral connections to $C B I-1$ interneurons. is incorporated in a program driven by CBI-2 (see also McCrohan and Kyriakides, 1989 , for discussion of $\mathrm{CVI}_{\mathrm{a}}$ and $\mathrm{CVI}_{\mathrm{b}}$ in Lymnaea). Thus, our findings suggest that careful attention must be paid to exactly how a cell is defined as being either phasic or tonic, that is, how it behaves when recruited into an ongoing motor program versus how it behaves when driven by constant-current intracellular stimulation.

\section{Functional considerations}

A major question regarding the neural control of feeding and other complex behaviors is how a coordinated, unified response is selected and generated by the activity of the nervous system. Current thinking relies on two conceptual models. One postulates that there is highly local control of behavior, and that responses are selected by the divergent actions of a few critical neurons. In the extreme case, it has been suggested that individual neurons, which have been termed command neurons, are necessary and sufficient for the elicitation of specific behavioral responses (Kupfermann and Weiss, 1978, 1986). A second model postulates that the generation of complex behavior is an emergent property of many ncurons that operate in parallel and in a distributed fashion (Davis, 1976; Mpitsos and Cohan, 1986; Kien, 1990). In some instances, it has been suggested that decisions to respond reflect some type of neuronal consensus that is based on the activity of a majority of neurons (Davis, 1976; Kein, 1990). A related notion is that various neurons contribute to a decision by playing different roles. As suggested by the analyses of complex networks, it is possible that the roles of individual neurons are not easily specifiable by simple language and that their contribution to behavior varies depending on the activity of the other neurons in the circuit and on the particular behavior being expressed (see, e.g., Hinton et al., 1986). One approach to distinguishing between these divergent models is to attempt to determine if individual neurons can elicit behaviors and, if so, whether there are many such neurons and whether they play distinctive roles. The current data tilt toward the idea that the consummatory aspects of feeding in Aplysia are under the local control of a relatively few "command-like" neurons, each of which has distinctive properties and may play a specific role in the generation of one or more consummatory responses. We are currently exploring the possible functional roles of these cells.

\section{References}

Arshavsky YI, Deliagina TG, Orlovsky GN, Panchin YV (1988) Control of feeding movements in the freshwater snail Planorbis corneus. III. Organization of the feeding rhythm generator. Exp Brain Res 70: 332-341. 
Audesirk G, Audesirk T (1980) Complex mechanoreceptors in Tritonia diomedea. I. Responses to mechanical and chemical stimuli. J Comp Physiol A 141:101-109.

Benjamin PR (1983) Gastropod feeding: behavioural and neural analysis of a complex multicomponent system. In: Neural origin of rhythmic movements (Roberts A, Roberts B, eds), pp 159-193. Cambridge: Society for Experimental Biology.

Benjamin PR, Elliott CJH (1989) Snail feeding oscillator: the central pattern generator and its control by modulatory interneurons. In: Neuronal and cellular oscillators (Jacklet JW, ed), pp 173-214. New York: Dekker.

Bicker G, Davis WJ, Matera EM (1982) Chemoreception and mechanoreception in the gastropod mollusc Pleurobranchaea californica. II. Neuroanatomical and intracellular analysis of afferent pathways. J Comp Physiol A 149:235-250.

Byrne JH (1980) Quantitative aspects of ionic conductance mechanisms contributing to firing pattern of motor cells mediating inking behavior in Aplysia californica. J Neurophysiol 43:651-668.

Carefoot TH (1987) Aplysia: its biology and ecology. Oceanogr Mar Biol Annu Rev 25:167-284.

Carew TJ, Kandel ER (1977) Inking in Aplysia californica. II. Central program for inking. J Neurophysiol 40:708-720.

Chiel HJ, Weiss KR, Kupfermann I (1986) An identitied histaminergic neuron modulates feeding motor circuitry in Aplysia. J Neurosci 6: 2427-2450.

Chiel HJ, Kupfermann I, Weiśs KR (1988) An identified histaminergic neuron can modulate the outputs of buccal-cerebral interneurons in Aplysia via presynaptic inhibition. J Neurosci 8:49-63.

Cohan CS, Mpitsos GJ (1983a) The generation of rhythmic activity in a distributed motor system. J Exp Biol 102:25-42.

Cohan CS, Mpitsos GJ (1983b) Selective recruitment of intcrganglionic interneurones during different motor patterns in Pleurobranchaea. J Exp Biol 102:43-57.

Cohen JL, Weiss KR, Kupfermann I (1978) Motor control of buccal muscles in Aplysia. J Neurophysiol 41:157-180.

Croll RP, Davis WJ (1987) Neural mechanisms of motor program switching in Pleurobranchaea. In: Higher brain functions: recent explorations of the brain's emergent properties (Wise SP, ed), pp 157179. New York: Wiley.

Croll RP, Davis WJ, Kovac MP (1985a) Neural mechanisms of motor program switching in the mollusc Pleurobranchaea. I. Central motor programs underlying ingestion, egestion, and the "neutral" rhythm(s). J Neurosci 5:48-55.

Croll RP, Kovac MP, Davis WJ (1985b) Neural mechanisms of motor program switching in the mollusc Pleurobranchaea. II. Rolc of the ventral white cell, anterior ventral, and B3 buccal neurons. J Neurosci 5:56-63.

Croll RP, Kovac MP, Davis WJ, Matera EM (1985c) Neural mechanisms of motor program switching in the mollusc Pleurobranchaea. III. Role of the paracerebral neurons and other identified brain neurons. J Neurosci 5:64-71.

Cropper EC, Lloyd PE, Reed W, Tenenbaum R, Kupfermann I, Weiss KR (1987) Multiple neuropeptides in cholinergic motor neurons of Aplysia: evidence for modulation intrinsic to the motor circuit. Proc Natl Acad Sci USA 84:3486-3490.

Cropper EC, Kupfermann I, Weiss KR (1990) Differential firing patterns of the peptide-containing cholinergic motor neurons B15 and B16 during feeding behavior in Aplysia. Brain Res 522:176-179.

Davis WJ (1976) Organizational concepts in the central motor networks of invertebrates. In: Neural control of locomotion (Herman RM, Grillner S, Stein PSG, Stuart DG, eds), pp 265-292. New York: Plenum.

Davis WJ, Gillette R, Kovac MP, Croll RP, Matera EM (1983) Organization of synaptic inputs to the paracerebral feeding command interneurons of Pleurobranchaea californica. III. Modifications induced by experience. J Neurophysiol 49:1557-1572.

Delaney K, Gelperin A (1990a) Cerebral interneurons controlling fictive feeding in Limax maximus. I. Anatomy and criteria for re-identification. J Comp Physiol A 166:297-310.

Delaney K, Gelperin A (1990b) Cerebral interneurons controlling fictive feeding in Limax maximus. II. Initiation and modulation of fictive feeding. J Comp Physiol A 166:311-326.

Delaney K, Gelperin A (1990c) Cerebral interncurons controlling fictive feeding in Limax maximus. III. Integration of sensory inputs. J Comp Physiol A 166:327-343.
Elliott CJH, Benjamin PR (1985) Interactions of pattern-generating interneurons controlling feeding in Lymnaea stagnalis. J Neurophysiol 54:1396-1411.

Elliott CJH, Benjamin PR (1989) Esophageal mechanoreceptors in the feeding system of the pond snail, Lymnaea stagnalis. J Neurophysiol 61:727-736.

Fiore L, Geppetti L (1981) Neural control of buccal mass activity in Aplysia. In: Advances in physiological sciences, Vol 23, Neurobiology of invertebrates (Salanki J, ed), pp 201-223. New York: Pergamon.

Fiore L, Meunier JM (1979) Synaptic connections and functional organization in Aplysia buccal ganglia. J Neurobiol 10:13-29.

Fredman SM, Jahan-Parwar B (1977) Identifiable cerebral motoneurons mediating an anterior tentacular withdrawal reflex in Aplysia. $\mathbf{J}$ Neurophysiol 40:608-615.

Fredman SM, Jahan-Parwar B (1980) Processing of chemosensory and mechanosensory information in identifiable Aplysia neurons. Comp Biochem Physiol 66A:25-34.

Furness JB, Costa M, Wilson AJ (1977) Water-stable fluorophores, produced by reaction with aldehyde solutions, for the histochemical localization of catechol- and indolethylamines. Histochemistry 52 : 159-170.

Gardner D, Kandel ER (1977) Physiological and kinetic properties of cholinergic receptors activated by multiaction interneurons in buccal ganglia of Aplysia. J Neurophysiol 40:333-348.

Gelperin A (1981) Synaptic modulation by identified serotonin neurons. In: Serotonin, neurotransmission and behavior (Jacobs BL, Gelperin A, eds), pp 288-304. Cambridge, MA: MIT Press.

Gelperin A, Chang JJ, Reingold SC. (1978) Feeding motor program in Limax. I. Neuromuscular correlates and control by chemosensory input. J Neurobiol 9:285-300.

Gillette MU, Gillette R (1983) Bursting neurons command consummatory feeding behavior and coordinated visceral receptivity in the predatory mollusk Pleurobranchaea. J Neurosci 3:1791-1806.

Gillette R, Kovac MP, Davis WJ (1978) Command neurons in Pleurobranchaea receive synaptic feedback from the motor network they excite. Science 199:798-801.

Gillette R, Kovac MP, Davis WJ (1982) Control of feeding motor output by paracerebral neurons in brain of Pleurobranchaea californica. J Neurophysiol 47:885-908.

Goldstein RS, Schwartz JH (1989) Catecholamine neurons in Aplysia: improved light-microscopic resolution and ultrastructural study using paraformaldehyde and glutaraldehyde (FaGlu) cytochemistry. J Neurobiol 20:203-218.

Granzow B, Kater SB (1977) Identified higher-order neurons controlling the feeding motor program of Helisoma. Neuroscience 2: 1049-1063.

Hall DH, Russell RL (1991) The posterior nervous system of the nematode Caenorhabditis elegans: serial reconstruction of identified neurons and complete pattern of synaptic interactions. J Neurosci 11: $1-22$.

Hinton GE, McClelland JL, Rumelhart DE (1986) Distributed representations. In: Parallel distributed processing. Explorations in the microstructure of cognition. Vol 1, Foundations (Rumelhart DE, McClelland JL, PDP Research Group, eds), pp 77-109. Cambridge, MA: MIT Press.

Jahan-Parwar B, Fredman SM (1976) Cerebral ganglion of Aplysia: cellular organization and origin of nerves. Comp Biochem Physiol 54A:347-357.

Jahan-Parwar B, Wilson AH Jr, Fredman SM (1983) Role of proprioceptive reflexes in control of feeding muscles of Aplysia. J Neurophysiol 49:1469-1480.

Kandel ER, Wachtel H (1968) The functional organization of neural aggregates in Aplysia. In: Physiological and biochemical aspects of nervous integration (Carlson FD, ed), pp 17-65. Englewood Cliffs, NJ: Prentice-Hall.

Kater SB (1974) Feeding in Helisoma trivolvis: the morphological and physiological bases of a fixed action pattern. Am Zool 14:1017-1036.

Kater SB, Rowell CHF (1973) Integration of sensory and centrally programmed components in generation of cyclical feeding activity of Helisoma trivolvis. J Neurophysiol 36:142-155.

Kemenes G, Benjamin PR (1989) Appetitive learning in snails shows characteristics of conditioning in vertebrates. Brain Res 489:163-166.

Kicn J (1990) Ncuronal activity during spontancous walking-I. Starting and stopping. Comp Biochem Physiol 95A:607-621.

King MS, Delaney K, Gelperin A (1987) Acetylcholine activates ce- 
rebral interneurons and feeding motor program in Limax maximus. J Neurobiol 18:509-530.

Kirk MD (1989) Premotor neurons in the feeding system of Aplysia californica. J Neurobiol 20:497-512.

Kovac MP, Davis WJ, Matera E, Gillette R (1982) Functional and structural correlates of cell size in paracerebral neurons of Pleurobranchaea californica. J Neurophysiol 47:909-927.

Kovac MP, Davis WJ, Matera EM, Croll RP (1983) Organization of synaptic inputs to paracerebral feeding command interneurons of Pleurobranchaea californica. I. Excitatory inputs. J Neurophysiol 49: $1517-1538$.

Kovac MP, Matera EM, Volk PJ, Davis WJ (1986) Food avoidance learning is accompanied by synaptic attenuation in identified interneurons controlling feeding behavior in Pleurobranchaea. J Neurophysiol 56:891-905.

Kupfermann I (1974a) Feeding behavior in Aplysia: a simple system for the study of motivation. Behav Biol 10:1-26.

Kupfermann I (1974b) Dissociation of the appetitive and consummatory phases of feeding behavior in Aplysia: a lesion study. Behav Biol 10:89-97.

Kupfermann I, Weiss KR (1978) The command neuron concept. Behav Brain Sci 1:3-39.

Kupfermann I, Weiss KR (1986) Command performance. Behav Brain Sci 9:736-739.

Leonard JL, Lukowiak K (1986) The behavior of Aplysia californica Cooper (Gastropoda: Opisthobranchia): I. Ethogram. Behaviour 98 320-360.

Lloyd PE, Kupfermann I, Weiss KR (1988) Central peptidergic neurons regulate gut motility in Aplysia. J Neurophysiol 59:1613-1626.

London JA, Gillette R (1984) Functional roles and circuitry in an inhibitory pathway to feeding command neurones in Pleurobranchaea. J Exp Biol 113:423-446.

McCaman RE, Weinreich D (1985) Histaminergic synaptic transmission in the cerebral ganglion of Aplysia. J Neurophysiol 53:10161037.

McClellan AD (1982a) Movements and motor patterns of the buccal mass of Pleurobranchaea during feeding, regurgitation and rejection. J Exp Biol 98:195-211.

McClellan AD (1982b) Re-examination of presumed feeding motor activity in the isolated nervous system of Pleurobranchaea. J Exp Biol 98:213-228.

McClellan AD (1983a) Higher order neurons in the cerebral ganglion of Pleurobranchaea have diverse effects on buccal motor patterns. J Comp Physiol A 153:533-541.

McClellan AD (1983b) Higher order neurons in buccal ganglia of Pleurobranchaea elicit vomiting motor activity. J Neurophysiol 50: 658-670.

McCrohan CR (1988) Modification of central pattern generation in invertebrates. Comp Biochem Physiol 90A:17-22.

McCrohan CR, Kyriakides MA (1989) Cerebral interneurones controlling feeding motor output in the snail Lymnaea stagnalis. J Exp Biol 147:361-374.

Morielli AD, Matera EM, Kovac MP, Shrum RG, McCormack KJ, Davis WJ (1986) Cholinergic suppression: a posisynaptic mechanism of long-term associative learning. Proc Natl Acad Sci USA 83: 4556-4560.

Mpitsos GJ, Cohan CS (1986) Convergence in a distributed nervous system: parallel processing and self-organization. J Neurobiol 17:517545.

Murphy AD (1990) An identified pleural ganglion interneuron inhibits patterned motor activity in the buccal ganglia of the snail, Helisoma. Brain Res 525:300-303.

Murphy AD, Lukowiak K, Stell WK (1985) Peptidergic modulation of patterned motor activity in identified neurons of Helisoma. Proc Natl Acad Sci USA 82:7140-7144.

Nagahama T, Takata M (1990) Innervation of buccal muscles by multifunctional MA1 neurons in Aplysia kurodai. J Comp Physiol A 167:1-10.

Ono JK, McCaman RE (1980) Identification of additional histaminergic neurons in Aplysia: improvement of single cell isolation techniques for in tandem physiological and chemical studies. Neuroscience 5: 835-840.

Pentreath VW, Berry MS, Osborne NN (1982) The serotonergic cerebral cells in gastropods. In: Biology of serotonergic transmission (Osborne NN, ed), pp 457-513. New York: Wiley.
Plummer MR, Kirk MD (1990) Premotor neurons B51 and B52 in the buccal ganglia of Aplysia californica: synaptic connections, effects on ongoing motor rhythms, and peptide modulation. J Neurophysiol 63:539-558.

Quicke DLJ, Brace RC (1979) Differential staining of cobalt- and nickel-filled neurones using rubeanic acid. J Microsc 115:161-163.

Rao G, Barnes CA, McNaughton BL (1986) Intracellular fluorescent staining with carboxyfluorescein: a rapid and reliable method for quantifying dye-coupling in mammalian central nervous system. J Neurosci Meth 16:251-263.

Rathouz MM, Kirk MD (1988) Localization of catecholamines in the buccal ganglia of Aplysia californica. Brain Res 458:170-175.

Rose RM, Benjamin PR (1981) Interneuronal control of feeding in the pond snail Lymnaea stagnalis. I. Initiation of feeding cycles by a single buccal interneurone. J Exp Biol 92:187-201.

Rosen SC, Weiss KR, Kupfermann I (1979) Response properties and synaptic connections of mechanoafferent neurons in cerebral ganglion of Aplysia. J Neurophysiol 42:954-974.

Rosen SC, Weiss KR, Cohen JL, Kupfermann I (1982) Interganglionic cerebral-buccal mechanoafferents of Aplysia: receptive fields and synaptic connections to different classes of neurons involved in feeding behavior. J Neurophysiol 48:271-288.

Rosen SC, Miller MW, Weiss KR, Kupfermann I (1987) Control of buccal motor programs in Aplysia by identified neurons in the cerebral ganglion. Soc Neurosci Abstr 13:1061.

Rosen SC, Miller MW, Weiss KR, Kupfermann I (1988) Activity of CBI-2 of Aplysia elicits biting-like responses. Soc Neurosci Abstr 14: 608.

Rosen SC, Susswein AJ, Cropper EC, Weiss KR, Kupfermann I (1989a) Selective modulation of spike duration by serotonin and the neuropeptides, FMRFamide, $S_{C} P_{B}$, buccalin and myomodulin in different classes of mechanoafferent neurons in the cerebral ganglion of Aplysia. J Neurosci 9:390-402.

Rosen SC, Teyke T, Weiss KR, Kupfermann I (1989b) Identification and characterization of putative dopamine-containing neurons implicated in the control of feeding behavior in Aplysia. Soc Neurosci Abstr 15:736.

Rosen SC, Weiss KR, Goldstein RS, Kupfermann I (1989c) The role of a modulatory neuron in feeding and satiation in Aplysia: effects of lesioning of the serotonergic metacerebral cells. J Neurosci 9:15621578.

Spray DC, Spira ME, Bennett MVL (1980a) Peripheral fields and branching patterns of buccal mechanosensory neurons in the opisthobranch mollusc, Navanax inermis. Brain Res 182:253-270.

Spray DC, Spira ME, Bennett MVL (1980b) Synaptic connections of buccal mechanosensory neurons in the opisthobranch mollusc, $\mathrm{Na}$ vanax inermis. Brain Res 182:271-286.

Steinberg TH, Newman AS, Swanson JA, Silverstein SC (1987) Macrophages possess probenecid-inhibitable organic anion transporters that remove fluorescent dyes from the cytoplasmic matrix. J Cell Biol 105:2695-2702.

Stewart WW (1978) Functional connections between cells as revealed by dye-coupling with a highly fluorescent naphthalimide tracer. Cell 14:741-759.

Susswein AJ, Byrne JH (1988) Identification and characterization of neurons initiating patterned neural activity in the buccal ganglia of Aplysia. J Neurosci 8:2049-2061.

Susswein AJ, Kupfermann I, Weiss KR (1976) The stimulus control of biting in Aplysia. J Comp Physiol A 108:75-96.

Susswein AJ, Weiss KR, Kupfermann I (1978) The effects of food arousal on the latency of biting in Aplysia. J Comp Physiol A 123: $31-41$.

Teyke T, Weiss KR, Kupfermann I (1989) A subpopulation of cerebral B cluster neurones of Aplysia californica is involved in defensive head withdrawal but not appetitive head movements. J Exp Biol 147:120.

Teyke T, Weiss KR, Kupfermann I (1990) Appetitive feeding behavior of Aplysia: behavioral and neural analysis of directed head turning. J Neurosci 10:3922-3934.

Trimble DL, Barker DL (1984) Activation by dopamine of patterned motor output from the buccal ganglia of Helisoma trivolvis. J Neurobiol 15:37-48.

Tritt SH, Lowe IP, Byrne JH (1983) A modification of the glyoxylic acid induced histofluorescence technique for demonstration of cate- 
cholamines and serotonin in tissues of Aplysia californica. Brain Res 259:159-162.

Tuersley MD, McCrohan CR (1988) Serotonergic modulation of patterned motor output in Lymnaea stagnalis. J Exp Biol 135:473-486.

Weiss KR, Kupfermann I (1976) Homology of the giant serotonergic ncurons (mctaccrebral cclls) in Aplysia and pulmonate molluscs. Brain Res 117:33-49.

Weiss KR, Cohen JL, Kupfermann I (1978) Modulatory control of buccal musculature by a serotonergic neuron (metacerebral cell) in Aplysia. J Neurophysiol 41:181-203.

Weiss KR, Koch UT, Koester J, Rosen SC, Kupfermann I (1982) The role of arousal in modulating feeding behavior of Aplysia: neural and behavioral studies. In: The neural bases of feeding and reward (Hoebel BG, Novin D, eds), pp 25-57. Brunswick, ME: Haer Institute.

Weiss KR, Shapiro E, Kupfermann I (1986a) Modulatory synaptic actions of an identified histaminergic neuron on the serotonergic metacerebral cell of Aplysia. J Neurosci 6:2393-2402.
Weiss KR, Chiel HJ, Koch U, Kupfermann I (1986b) Activity of an identified histaminergic neuron, and its possible role in arousal of feeding behavior in semi-intact Aplysia. J Neurosci 6:2403-2415.

Weiss KR, Chiel HJ, Kupfermann I (1986c) Sensory function and gating of histaminergic neuron $\mathrm{C} 2$ in Aplysia. J Neurosci 6:24162426.

Wieland SJ, Jahn E, Gelperin A (1987) Localization and synthesis of monoamines in regions of Limax CNS controlling feeding behavior. Comp Biochem Physiol 86C:125-130.

Willows AOD (1978) Physiology of feeding in Tritonia. I. Behavior and mechanics. Mar Behav Physiol 5:115-135.

Willows AOD (1980) Physiological basis of feeding behavior in Tritonia diomedea. II. Neuronal mechanisms. J Neurophysiol 44:849861. 